\title{
Three Drosophila Liprins Interact to Control Synapse Formation
}

\author{
Sergio Astigarraga, ${ }^{*}$ Kerstin Hofmeyer, ${ }^{\star}$ Reza Farajian, and Jessica E. Treisman \\ Kimmel Center for Biology and Medicine of the Skirball Institute and Department of Cell Biology, New York University School of Medicine, New York, \\ New York 10016
}

Liprin- $\alpha$ proteins are adaptors that interact with the receptor protein tyrosine phosphatase leukocyte common antigen-related (LAR) and other synaptic proteins to promote synaptic partner selection and active zone assembly. Liprin- $\beta$ proteins bind to and share homology with Liprin- $\alpha$ proteins, but their functions at the synapse are unknown. The Drosophila genome encodes single Liprin- $\alpha$ and Liprin- $\beta$ homologs, as well as a third related protein that we named Liprin- $\gamma$. We show that both Liprin- $\beta$ and Liprin- $\gamma$ physically interact with Liprin- $\alpha$ and that Liprin- $\gamma$ also binds to LAR. Liprin- $\alpha$ mutations have been shown to disrupt synaptic target layer selection by R7 photoreceptors and to reduce the size of larval neuromuscular synapses. We have generated null mutations in Liprin- $\beta$ and Liprin- $\gamma$ to investigate their role in these processes. We find that, although Liprin- $\alpha$ mutant R7 axons terminate before reaching the correct target layer, Liprin- $\beta$ mutant R7 axons grow beyond their target layer. Larval neuromuscular junction size is reduced in both Liprin- $\alpha$ and Liprin- $\beta$ mutants, and further reduced in double mutants, suggesting independent functions for these Liprins. Genetic interactions demonstrate that both Liprin proteins act through the exchange factor Trio to promote stable target selection by R7 photoreceptor axons and growth of neuromuscular synapses. Photoreceptor and neuromuscular synapses develop normally in Liprin- $\gamma$ mutants; however, removing Liprin- $\gamma$ improves R7 targeting in Liprin- $\alpha$ mutants, and restores normal neuromuscular junction size to Liprin- $\beta$ mutants, suggesting that Liprin- $\gamma$ counteracts the functions of the other two Liprins. We propose that context-dependent interactions between the three Liprins modulate their functions in synapse formation.

\section{Introduction}

Synapse formation is triggered by interactions between specific adhesion molecules on the presynaptic and postsynaptic cells (Biederer and Stagi, 2008). Subsequent assembly of the presynaptic active zone involves a complex network of cytoskeletal and adaptor molecules. Central to this network is the scaffolding protein Liprin- $\alpha$ (Spangler and Hoogenraad, 2007). Liprin- $\alpha$ proteins were first isolated as binding partners of the receptor protein tyrosine phosphatase (RPTP) leukocyte common antigen-related (LAR) (Serra-Pagès et al., 1995; Kaufmann et al., 2002). They have since been shown to recruit presynaptic proteins that regulate neurotransmitter release, to act as adaptors for axonal transport, and to interact with postsynaptic proteins im-

\footnotetext{
Received April 12, 2010; revised Aug. 26, 2010; accepted Sept. 17, 2010.

This work was supported by March of Dimes Birth Defects Foundation Grant 1-FY04-101 and National Institutes of Health Grant GM089799. S.A. was supported by a postdoctoral fellowship from the Spanish Ministry of Education and Science. We are grateful to Hugo Bellen, Claude Desplan, Barry Dickson, the Bloomington Drosophila Stock Center, the Drosophila Genomics Resource Center, the Vienna Drosophila RNAi Center, and the Developmental Studies Hybridoma Bank for fly stocks and reagents. We thank Tashana Williams-Moye and Myra Perez for technica assistance. This manuscript was improved by the critical comments of Minrong Ai, Kevin Legent, Jean-Yves Roignant, and Josie Steinhauer.

*S.A. and K.H. contributed equally to this work.

Correspondence should be addressed to Jessica E. Treisman, Kimmel Center for Biology and Medicine of the Skirball Institute and Department of Cell Biology, New York University School of Medicine, 540 First Avenue, New York, NY 10016. E-mail: jessica.treisman@med.nyu.edu.

R. Farajian's present address: Department of Physiology and Neuroscience, New York University School of Medicine, 540 First Avenue, New York, NY 10016.

DOI:10.1523/JNEUROSCI.1862-10.2010

Copyright $\odot 2010$ the authors $\quad 0270-6474 / 10 / 3015358-11 \$ 15.00 / 0$
}

plicated in AMPA receptor trafficking (Zhen and Jin, 1999; Schoch et al., 2002; Wyszynski et al., 2002; Ko et al., 2003a,b; Shin et al., 2003; Miller et al., 2005; Olsen et al., 2005; Dai et al., 2006; Patel et al., 2006; Dickinson et al., 2009; Wagner et al., 2009).

Drosophila Liprin- $\alpha$ promotes normal synaptogenesis by photoreceptors and motor neurons. Photoreceptors R1-R6 terminate in the lamina, where Liprin- $\alpha$ is required for the axons from each ommatidium to connect to six different cartridges (Choe et al., 2006). The color-sensitive photoreceptors R7 and R8 project through the lamina and terminate in distinct layers of the medulla, R8 in M3 and R7 in the deeper M6 layer. In Liprin- $\alpha$ mutants, most R7 axons terminate prematurely in the M3 layer (Choe et al., 2006; Hofmeyer et al., 2006). At the larval neuromuscular junction (NMJ), Liprin- $\alpha$ mutants show reduced numbers of synaptic boutons, enlarged active zones, and impaired synaptic transmission (Kaufmann et al., 2002). Conversely, increased Liprin- $\alpha$ stability increases NMJ size (van Roessel et al., 2004). Since Liprin- $\alpha$ mutant phenotypes strongly resemble Lar phenotypes (Clandinin et al., 2001; Maurel-Zaffran et al., 2001; Kaufmann et al., 2002), a complex containing both proteins may regulate synaptogenesis.

The four mammalian Liprin- $\alpha$ proteins and the single Drosophila Liprin- $\alpha$ have $\mathrm{N}$-terminal coiled-coil domains and C-terminal Liprin homology domains (LHDs), consisting of three sterile $\alpha$ motifs (SAMs) (Serra-Pagès et al., 1998; Kaufmann et al., 2002). The LHD mediates binding to LAR and to two related mammalian proteins, Liprin- $\beta 1$ and Liprin- $\beta 2$, whereas the $\mathrm{N}$-terminal domains of Liprin- $\alpha$ and Liprin- $\beta$ proteins mediate 
homodimerization (Serra-Pagès et al., 1998; Hofmeyer et al., 2006). Liprin- $\beta 1$ interacts with the metastasis-associated protein S100A4 (Kriajevska et al., 2002) and promotes lymphatic vessel integrity (Norrmén et al., 2010). An additional Liprin-related protein, isoform $\mathrm{E}$ of Kazrin, associates with the cytoskeleton of human keratinocytes and shows phosphorylation-dependent binding to LAR (Nachat et al., 2009).

We show here that the single Drosophila Liprin- $\beta$ and the Drosophila ortholog of KazrinE, which we have named Liprin- $\gamma$, both physically interact with Liprin- $\alpha$. However, the two genes exhibit different functional interactions in R7 targeting and NMJ growth. Liprin- $\beta$ contributes to NMJ synapse size in parallel with Liprin- $\alpha$ and prevents R7 axons from overshooting the M6 layer. Liprin- $\gamma$ antagonizes the function of Liprin- $\alpha$ in R7, and of Liprin- $\beta$ at the NMJ. The context-specific interactions among the three Liprins suggest that these two synapses differ in their assembly mechanisms.

\section{Materials and Methods}

Genetics. To identify X-ray-induced deletions of Liprin- $\gamma$, homozygous pBACf01268 $\left(w^{+}\right)$males were irradiated with $4000 \mathrm{rad}$ and crossed to $w$; $\mathrm{CyO} / \mathrm{Sco}$ females. Fifty-one $\mathrm{F}_{1} w^{-}$flies, of which 37 were fertile, were recovered of 55,049 screened. The extent of the deletions was characterized by determining which regions of the genomic sequence could be amplified by PCR from homozygous embryos, identified by lack of the CyO-Ubi-GFP balancer. Of the deletions that removed at least one end of the pBAC element, Liprin- $\gamma^{S 1}$ and Liprin- $\gamma^{H 1}$ were the smallest. Liprin$\gamma^{S 1}$ deletes the $5^{\prime}$ end of the pBAC element and part of the first intron of Liprin- $\gamma$, but does not extend as far as the upstream exon. Liprin- $\gamma^{H 1}$ deletes most of the Liprin- $\gamma$ gene, except for the most 5' untranslated exon. This deletion extends into the downstream gene Gp150 and fails to complement the bristle phenotype of $G p 150^{k 11120 b}$ (Flybase).

Liprin- $\beta$ excisions were obtained by crossing $\Delta 2-3, C y O ; P\{E P\} E Y 22999 /$ TM3 males to $w$; TM3/TM6B females and looking for $w^{-}$flies in the $\mathrm{F}_{1}$ progeny. One hundred independent excision lines were analyzed in pools by PCR with primers upstream and downstream of the P element; a smaller product was amplified from five lines and sequenced to determine the extent of the deletion.

Liprin- $\alpha$ Liprin- $\gamma$ recombinants were made using failure to complement $D f(2 R) 02311$ as an assay for Liprin- $\gamma^{S 1}$, since this chromosome carried an independent lethal mutation within the deficiency, and failure to complement Gp150 as an assay for Liprin- $\gamma^{H 1}$. The presence of the Liprin- $\gamma$ alleles was confirmed by PCR.

Viability tests were done in parallel by crossing males heterozygous for single or double Liprin mutations over CyO; TM6B or SM6-TM6B balancers to either Liprin- $\alpha$; Liprin- $\beta / \mathrm{SM} 6-\mathrm{TM} 6 \mathrm{~B}$ or Liprin- $\alpha$, Liprin- $\gamma$; Liprin- $\beta /$ SM6-TM6B females. The expected percentage of homozygous mutant adult flies in the progeny was calculated as one-half the number of balancer flies.

Other fly stocks used were Liprin- $\alpha^{o o s}$, panR7-lacZ (Hofmeyer et al., 2006), glass-lacZ (Moses and Rubin, 1991), Lar ${ }^{2127}$, Lar ${ }^{\text {c12 }}$ (MaurelZaffran et al., 2001), GMR-trio, elav-trio (Newsome et al., 2000), elav ${ }^{\text {Cl55 }}$ GAL4, sev-GAL4, how ${ }^{24 B}$-GAL4, Df(3L)BSC614, UAS-trio (Bloomington Drosophila Stock Center), UAS-trioRNAi (Vienna Drosophila RNAi Center), and UAS- $d c r 2$ (Dietzl et al., 2007). $w^{1118}$ flies were used as wild-type controls.

Transgenes. UAS-HA-LAR, UAS-HA-LARD2, UAS-HA-Liprin- $\alpha$, and UAS-Myc-Liprin- $\alpha$ have been described previously (Hofmeyer et al., 2006). UAS-HA-PTP69D-D2 was constructed by PCR to contain an $\mathrm{N}$-terminal HA-tag followed by PTP69D amino acids 1187-1462. UASMyc-Liprin- $\alpha \Delta$ C, a derivative of UAS-Myc-Liprin- $\alpha$, was made using an internal BamHI site for truncation after Ser 911; the open reading frame terminates after 8 aa (AAAARGYL) derived from the vector. pPac-V5Liprin- $\alpha$ was made using PCR to add a single copy of the V 5 tag to the $\mathrm{N}$ terminus of the full-length cDNA in the PPAC-PL vector.

UAS-HA-Liprin- $\beta$ was derived from cDNA clone RE16685 [Drosophila Genomics Resource Center (DGRC)]. The first 295 aa were PCR amplified and cloned into pUAST-HA, introducing an N-terminal HAtag, and the remainder of the sequence was added as a BglII/EcoRI
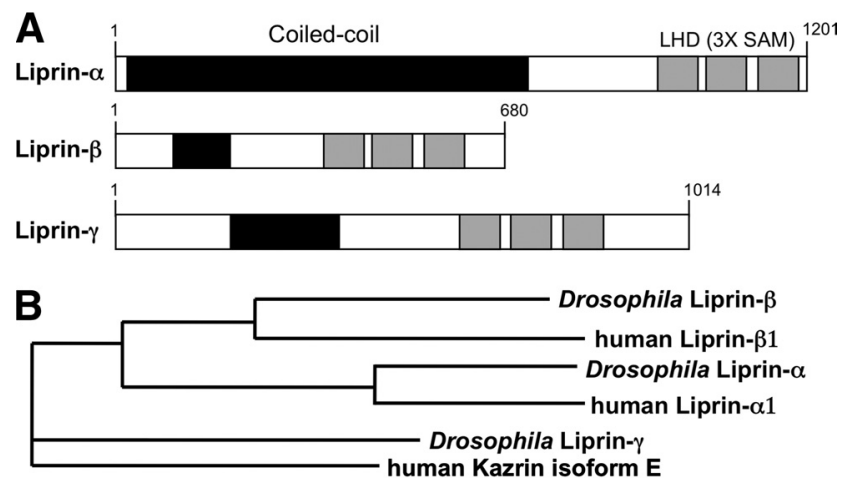

Figure 1. The Drosophila Liprin family. $\boldsymbol{A}$ shows a schematic of the structures of the three Drosophila Liprin proteins. Predicted coiled-coil domains (amino acids 32-680 in Liprin- $\alpha$, amino acids $93-185$ in Liprin- $\beta$, and amino acids 173-352 in Liprin- $\gamma$ ) are depicted by black boxes, and the three $C$-terminal SAM domains that constitute the LHD (amino acids 942-1186 in Liprin- $\alpha$, amino acids $359-602$ in Liprin- $\beta$, and amino acids 582-816 in Liprin- $\gamma$ ) are shaded. $\boldsymbol{B}$ shows a phylogram generated by ClustalW of the evolutionary distances between the three Drosophila Liprins and their closest human homologs. Liprin- $\gamma$ is equally homologous to both the other Drosophila Liprins, and most closely related to a specific isoform of the human Kazrin protein. Homologs of the other Kazrin isoforms, which do not contain the LHD, have not been reported in Drosophila.

(blunt-ended) fragment. For UAS-HA-Liprin- $\beta \Delta$ C, an NdeI-BglII fragment encoding amino acids 1-297 was excised from UAS-HA-Liprin$\beta \mathrm{FL}$ and cloned into pUAST-HA, adding an $\mathrm{N}$-terminal HA tag and eight vector sequence encoded amino acids (AAAARGYL) at the truncated $C$ terminus. To make the Liprin- $\beta$ RNA interference (RNAi) construct, the region of cDNA clone RE16685 encoding amino acids 15-294 was PCRamplified and cloned in tandem in a sense-antisense orientation into pUAST. pPAC-Myc-Liprin- $\beta$ was made using PCR to add five copies of the Myc epitope tag to the $\mathrm{N}$ terminus of the full-length cDNA in the pPAC-PL vector.

All Liprin- $\gamma$ expression constructs were derived from the DGRC fulllength cDNA clone RE30524. To make UAS-HA-Liprin- $\gamma$, the 286 aa $\mathrm{N}$-terminal to an internal BglII restriction site were PCR amplified and cloned into pUAST-HA, introducing an N-terminal HA tag, and the C terminus and $3^{\prime}$-untranslated region (UTR) were added as a BglII-KpnI restriction fragment. To express Liprin- $\gamma$ from the actin promoter, the full-length coding region was excised from UAS-HA-Liprin- $\gamma$, and cloned into pPacPL-5xMyc, adding five copies of the Myc epitope tag to the $\mathrm{N}$ terminus, or into pPacPL-V5, adding one copy of the V5 tag to the $\mathrm{N}$ terminus. Both C-terminal deletions of Liprin- $\gamma$ are derivatives of pPac-5xMyc-Liprin- $\gamma$ and were generated by blunt ending unique internal restriction sites and vector religation. For Liprin- $\gamma \Delta$ S23, DraIII was used to generate a truncation after Glu666 followed by 63 vectorencoded amino acids. For Liprin- $\gamma \Delta \mathrm{C}$, AscI was used for truncation after Ala584 followed by 5 vector-encoded amino acids (SSRPR). For Liprin$\gamma \Delta \mathrm{N}$, a cDNA region encoding the final 432 aa of Liprin- $\gamma$ and $957 \mathrm{bp}$ of 3'-UTR was PCR amplified. A KpnI site was added by PCR 5' of Trp582 to allow cloning into pPac5xMyc.

Cell culture and immunoprecipitation. Culture and transfection of $\mathrm{S}_{2} \mathrm{R}^{+}$cells was performed as described previously (Hofmeyer et al., 2006). Forty-eight hours after transient transfection, $\mathrm{S}_{2} \mathrm{R}^{+}$cells were rinsed briefly in $50 \mathrm{~mm}$ Tris, $\mathrm{pH} 7.5$, and lysed in ice-cold immunoprecipitation (IP) buffer [ $50 \mathrm{~mm}$ Tris, pH 7.5, $150 \mathrm{~mm} \mathrm{NaCl}, 1 \mathrm{~mm} \mathrm{NaF}, 1 \mathrm{~mm}$ EDTA, and $1 \%$ Nonidet $\mathrm{P}-40$ with protease inhibitors (Roche)]. Proteins were immunoprecipitated with $2 \mu \mathrm{g}$ of mouse anti-Myc 9E10 (Santa Cruz Biotechnology) or $1.5 \mu \mathrm{g}$ of rat anti-HA 3F10 (Roche). Protein G-agarose beads (Roche) were used for precipitation according to the manufacturer's instructions. Proteins were separated by SDS/PAGE, and blots were probed with mouse anti-Myc 9E10 (1:8000), rat anti-HA 3F10 (1:1000), or mouse anti-V5 (Invitrogen; 1:5000) in Tris-buffered saline/ $0.2 \%$ Tween 20 with $5 \%$ BSA, followed by horseradish peroxidase (HRP)coupled donkey anti-mouse or anti-rat secondary antibodies (1:8000; 
Jackson ImmunoResearch). Signal was detected by enhanced chemiluminescence (Pierce).

Immunohistochemistry and in situ hybridization. In situ hybridization to embryos and eye discs with antisense probes transcribed from either cDNA clones or PCR products amplified from genomic DNA was performed as previously described (Maurel-Zaffran and Treisman, 2000). Sense probes gave no signal when used in parallel.

Primary antibodies used were rabbit anti- $\beta$ galactosidase, to detect glass-lacZ and panR7-lacZ (1:2500; Cappel); Cy5-coupled goat anti-HRP, to detect neuronal membranes (1:200; Jackson ImmunoResearch); rabbit anti-Synaptotagmin (Syt) (1:2000; courtesy of Hugo Bellen, Baylor College of Medicine, Houston, TX); mouse antiChaoptin [mAb 24B10; 1:50; Developmental Studies Hybridoma Bank (DSHB)]; mouse antiDiscs large (Dlg) (mAb 4F3; 1:50; DSHB), mouse anti-Bruchpilot (Brp) (mAb nc82; 1:50; DSHB), and mouse anti-DGluR-IIA (mAb 8B4D2; 1:50; DSHB). Primary antibody incubations were performed overnight at $4^{\circ} \mathrm{C}$. Fluorescent secondary antibodies (and Cy-5 anti-HRP) were incubated for $2 \mathrm{~h}$ at $4^{\circ} \mathrm{C}$; these were goat anti-mouse and anti-rabbit Alexa 488 (1:400; Invitrogen) and donkey anti-mouse and anti-rabbit Cy5 (1:200; Jackson ImmunoResearch). Confocal images were collected on Zeiss LSM510 and Leica SP5 confocal microscopes.

Head sections and R7 quantifications. Adult heads were dissected in cold $0.1 \mathrm{M}$ phosphate buffer (PB), $\mathrm{pH} 7.4$, fixed in $4 \%$ formaldehyde in $\mathrm{PB}$ for $4 \mathrm{~h}$ at $4^{\circ} \mathrm{C}$, washed in $\mathrm{PB}$, and submerged in $25 \%$ sucrose overnight at $4^{\circ} \mathrm{C}$ for cryoprotection. Heads were then embedded in tissue freezing medium and frozen in dry ice/ethanol, and $12 \mu \mathrm{m}$ sections were cut on a cryostat. Sections were postfixed in $0.5 \%$ formaldehyde in $\mathrm{PB}$ for $30 \mathrm{~min}$ at room temperature and washed several times in $\mathrm{PB} / 0.1 \%$ Triton (PBT) before incubation with primary and secondary antibodies. All quantifications were done using maximumintensity projections of sections stained for the photoreceptor marker glass-lacZ. The "percentage of R7 axons overshooting the M6 layer" is the ratio of [long processes]/[termini at the M6 layer], whereas the "percentage of R7 axons beyond M3" was calculated as [termini at the M6 layer]/[columns at the M3 layer]. Samples were counted blind. Error bars represent SEM. ${ }^{\star} p<$ $0.05,{ }^{* *} p<0.001$, and ${ }^{* * *} p<0.0001$.

Larval NMJ preparations. Larvae were pinned to silicone plates, covered with cold $\mathrm{PB}, \mathrm{pH} 7.4$, and opened along the dorsal midline. Body contents were removed, and filets were fixed in $4 \%$ formaldehyde in $\mathrm{PB}$ for $15 \mathrm{~min}$ at room temperature. After several washes in PBT, filets were blocked in 3\% donkey serum in PBT for $1 \mathrm{~h}$ at $4^{\circ} \mathrm{C}$ before primary antibody incubation. Synaptic boutons were counted blind.

\section{Results}

The Drosophila genome encodes three Liprins

In addition to the previously described Liprin- $\alpha$ homolog (Kaufmann et al., 2002; Choe et al., 2006; Hofmeyer et al.,

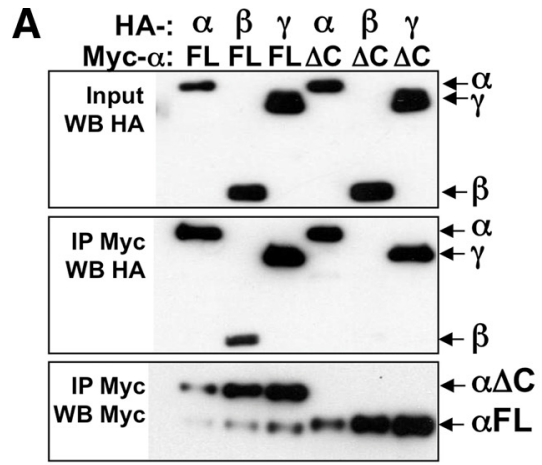

B
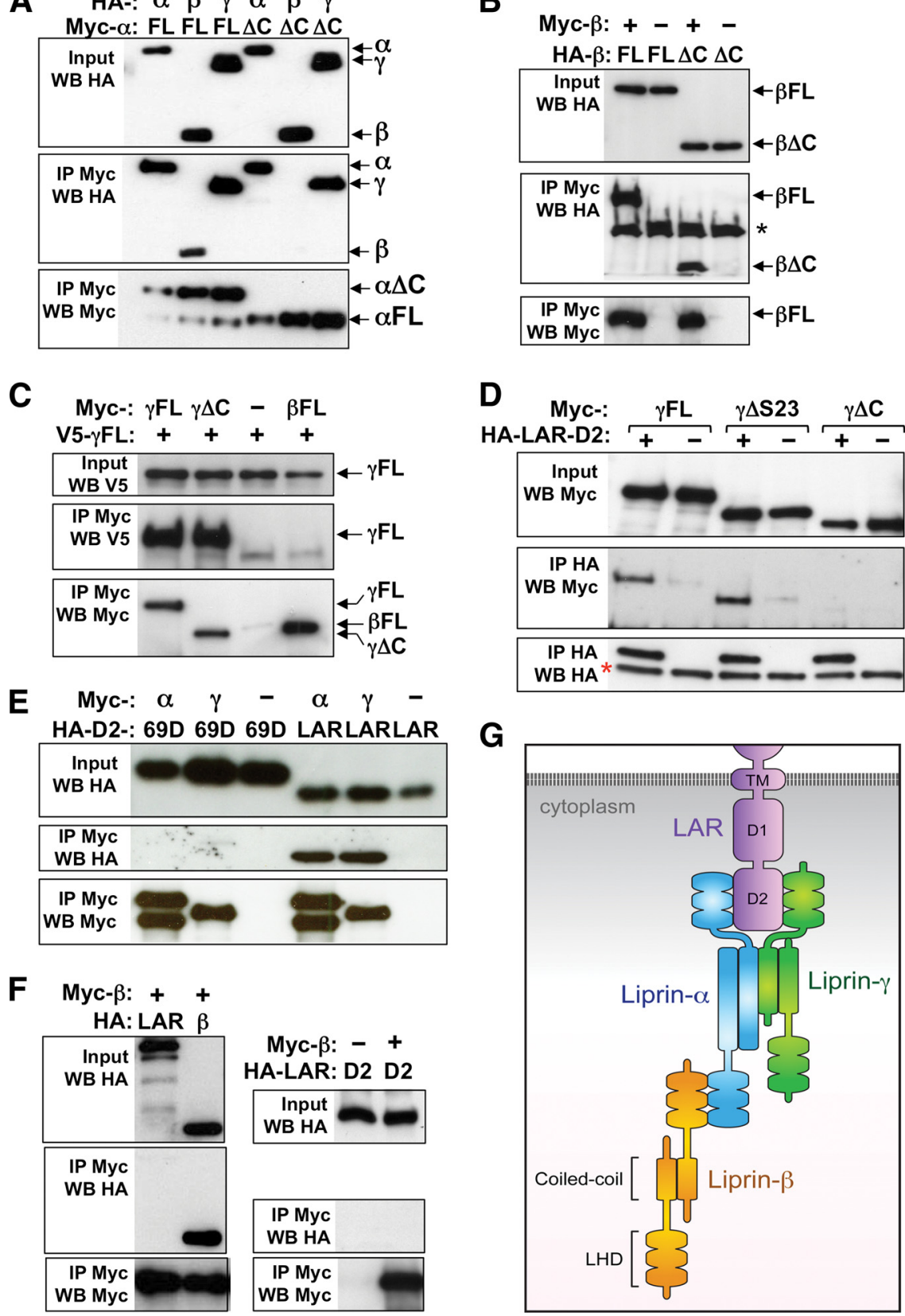

Figure 2. Liprin- $\beta$ and Liprin- $\gamma$ homodimerize and bind to Liprin- $\alpha$. $\boldsymbol{A}-\boldsymbol{E}$ show coimmunoprecipitations of epitope-tagged proteins expressed in $S 2 R^{+}$cells. In $A$, HA-tagged Liprin- $\alpha$, Liprin- $\beta$, or Liprin- $\gamma$ was pulled down with Myc-tagged full-length (FL) Liprin- $\alpha$ or Liprin- $\alpha$ lacking the LHD ( $\Delta C$ ) by IP with anti-Myc. The middle panel shows the IP blotted (WB) with anti-HA, the top panel shows the input lanes blotted with anti-HA, and the bottom panel shows the IP blotted with anti-Myc. Both forms of Liprin- $\alpha$ pulled down Liprin- $\alpha$ and Liprin- $\gamma$, but only full-length Liprin- $\alpha$ pulled down Liprin- $\beta$. B, HA-tagged full-length (FL) Liprin- $\beta$, or Liprin- $\beta$ lacking the LHD ( $\Delta C$ ), were pulled down with Myc-tagged Liprin- $\beta$ by immunoprecipitation with anti-Myc. Liprin- $\beta$ pulled down both forms of Liprin- $\beta$. The panels are labeled as in $A .{ }^{*}$ Nonspecific band. C, V5-tagged Liprin- $\gamma$ was pulled down with Myc-tagged full-length (FL) Liprin- $\gamma$, Liprin- $\gamma$ lacking the $L H D(\Delta C)$, or full-length Liprin- $\beta$ by immunoprecipitation with anti-Myc. Both forms of Liprin- $\gamma$, but not Liprin- $\beta$, could pull down Liprin- $\gamma$. D, Myc-tagged full-length (FL) Liprin- $\gamma$, or Liprin- $\gamma$ lacking the last two SAM domains ( $\Delta S 23)$ or the whole LHD $(\Delta C)$ were pulled down with the HA-tagged D2 domain of LAR by immunoprecipitation with anti-HA. LAR-D2 pulled down Liprin- $\gamma$ and Liprin- $\gamma \Delta S 23$, but not Liprin- $\gamma \Delta C$, implicating the first SAM domain of Liprin- $\gamma$ in the interaction with LAR. *Antibody heavy chain. $E$, The HA-tagged D2 domains of PTP69D (69D) or LAR were pulled down with Myc-tagged Liprin- $\alpha$ or Liprin- $\gamma$ by immunoprecipitation with anti-Myc. Liprin- $\alpha$ and Liprin- $\gamma$ pulled down LAR but not PTP69D. $\boldsymbol{F}$, HA-tagged full-length LAR, LAR-D2, or Liprin- $\beta$ were pulled down with Myc-tagged Liprin- $\beta$ by immunoprecipitation with anti-Myc. Liprin- $\beta$ pulled down Liprin- $\beta$ but not LAR or the LARD2 domain. In all panels, control lanes lacking any protein with the epitope tag recognized by the immunoprecipitating antibody are indicated by " -." G shows a schematic of the interactions detected in this study and others. Liprin- $\alpha$ and Liprin- $\gamma$ can bind to the D2 domain of LAR through their C-terminal SAM domains (Serra-Pagès et al., 1998). Liprin- $\alpha$ and Liprin- $\beta$ interact through their LHDs (Serra-Pagès et al., 1998), and Liprin- $\alpha$ and Liprin- $\gamma$ interact through the coiled-coil domain of Liprin- $\alpha$. All three Liprins can homodimerize through their N-terminal coiled-coil domains (Serra-Pagès et al., 1998; Hofmeyer et al., 2006). 


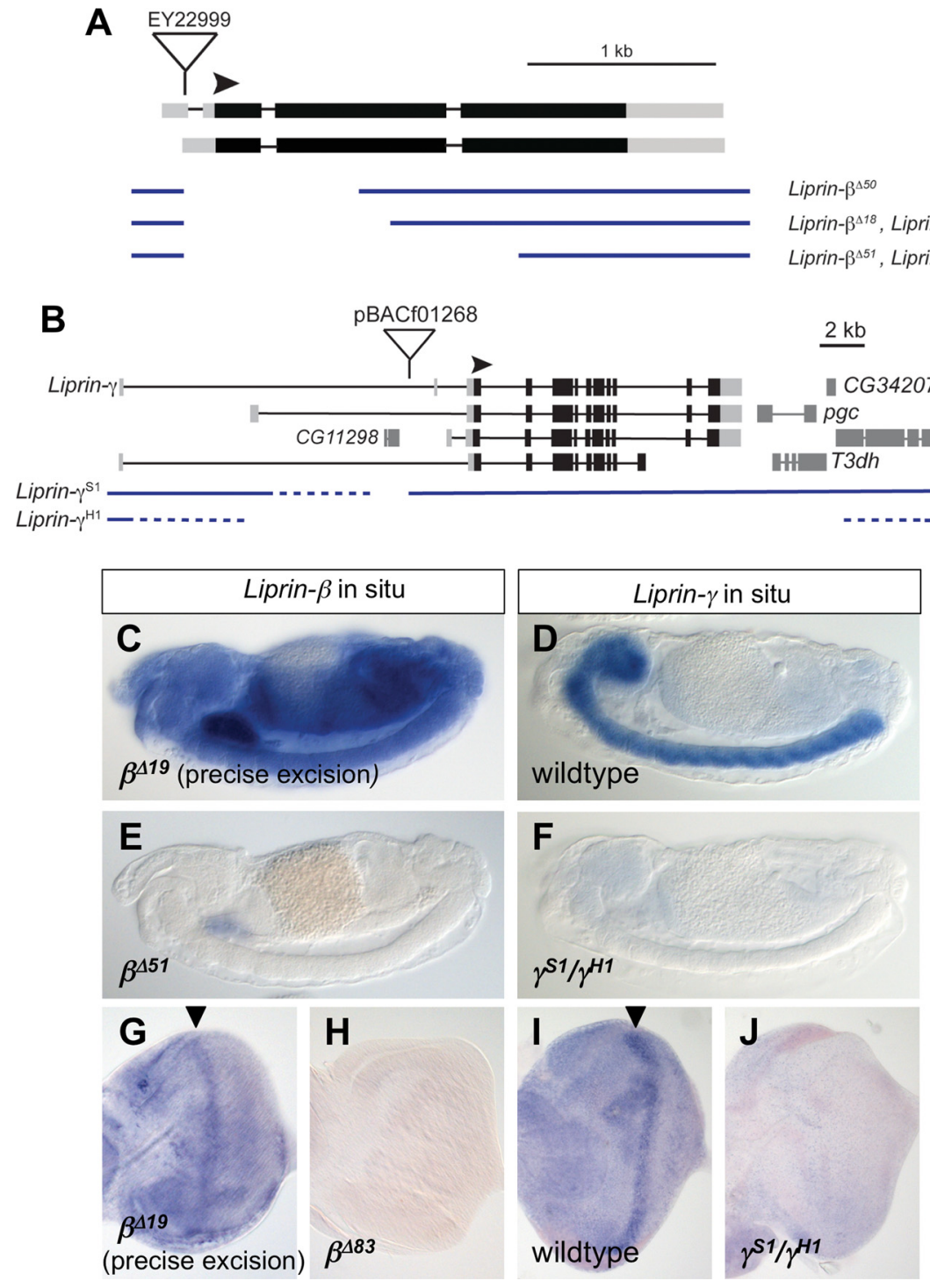

Figure 3. Generation of Liprin- $\beta$ and Liprin- $\gamma$ null mutants. $A$ and $\boldsymbol{B}$ show the genomic structures of Liprin- $\beta(\boldsymbol{A})$ and Liprin- $\gamma$ $(\boldsymbol{B})$. Exons are indicated by thick lines with untranslated regions in gray and translated regions in black, and introns by thin lines. The arrowheads indicate the start codons. Deletions induced by imprecise excision of $P\{E P\} E Y 22999(\boldsymbol{A})$ or by X-ray mutagenesis $(\boldsymbol{B})$ are shown below (blue lines). The endpoints of the deletions in $\boldsymbol{B}$ have not been precisely mapped; the dotted lines indicate the regions within which they fall. $\mathbf{C}-\boldsymbol{J}$ show in situ hybridization to stage 14 embryos $(\boldsymbol{C}-\boldsymbol{F})$ or third-instar eye imaginal discs $(\mathbf{G}-\boldsymbol{J})$ with Liprin- $\beta(\boldsymbol{C}, \boldsymbol{E}, \boldsymbol{G}, \boldsymbol{H})$ or Liprin- $\gamma(\boldsymbol{D}, \boldsymbol{F}, \boldsymbol{I}, \boldsymbol{J})$ probes. $\boldsymbol{C}, \boldsymbol{G}$, Precise excision of Liprin- $\beta\left(\right.$ Liprin- $\left.\beta^{\Delta 19}\right)$. D, I, Wild type. $\boldsymbol{E}$, Liprin- $\beta^{\Delta 51} . \boldsymbol{H}$, Liprin- $\beta^{\Delta 83} . \boldsymbol{F}, \mathbf{J}$, Liprin- $\gamma^{51} /$ Liprin- $\gamma^{H 1}$. The arrowheads in $\mathbf{G}$ and $\boldsymbol{I}$ indicate the morphogenetic furrow. Liprin- $\beta$ is broadly expressed and Liprin- $\gamma$ is specific to the nervous system in the embryo. Expression of both genes is abolished in the corresponding deletion mutants.

2006), the Drosophila genome encodes a single homolog of human Liprin- $\beta$ proteins (Serra-Pagès et al., 1998), CG10743, as well as a third protein, CG11206, that has approximately equal homology to Liprin- $\alpha$ and Liprin- $\beta$ (Fig. $1 A, B$ ). The closest human homolog of this protein is isoform E of Kazrin (Fig. 1B), which localizes to the nucleus and also associates with desmosomes and stable microtubules in human keratinocytes (Groot et al., 2004; Nachat et al., 2009). We have named the Drosophila protein Liprin- $\gamma$ (Fig. 1A), since the CG11206 locus does not encode homologs of the shorter Kazrin isoforms that lack the three SAM domains (Groot et al., 2004). Both Liprin- $\beta$ and Liprin- $\gamma$ contain stretches predicted by the Coils program (www. ch.embnet.org/software/COILS_form.html) to form coiled-coil structures (Fig. 1A).

\section{Liprin- $\alpha$ physically interacts with the other two Liprins}

Human Liprin- $\beta$ proteins were reported to bind to Liprin- $\alpha$ proteins through their C-terminal domains (Serra-Pagès et al., 1998). Using coimmunoprecipitation of epitope-tagged proteins expressed in cultured Drosophila S2R ${ }^{+}$cells as well as yeast two-hybrid assays, we found that Drosophila Liprin- $\beta$ likewise bound to Liprin- $\alpha$ and that this interaction was mediated by the C-terminal domains of both proteins (Fig. $2 A$ and data not shown). Liprin- $\gamma$ also bound to Liprin- $\alpha$ in coimmunoprecipitation assays, and the N-terminal domain of Liprin- $\alpha$ was sufficient for this interaction (Fig. 2A). However, Liprin- $\gamma$ showed no interaction with Liprin- $\beta$ (Fig. $2 C$ ). We have previously shown that Liprin- $\alpha$ can homodimerize through its N-terminal coiled-coil domain (Hofmeyer et al., 2006) (Fig. 2A). Similarly, homodimerization mediated by the $\mathrm{N}$-terminal domains of both Liprin- $\beta$ and Liprin- $\gamma$ was detected by coimmunoprecipitation of two differently tagged forms of each protein (Fig. $2 B, C)$. Like Liprin- $\alpha$ and human KazrinE (Nachat et al., 2009), Liprin- $\gamma$ could also coimmunoprecipitate the distal phosphatase domain (D2) of LAR (Fig. 2D,E). LAR binding required the first SAM domain in the LHD of Liprin- $\gamma$, but not the second and third SAM domains (Fig. 2D). This interaction was specific, since Liprin- $\beta$ did not coimmunoprecipitate either full-length LAR or its D2 domain (Fig. $2 F$ ), and Liprin- $\alpha$ and Liprin- $\gamma$ failed to interact with the D2 domain of PTP69D, a related RPTP also involved in R7 targeting and NMJ synapse growth (Hofmeyer and Treisman, 2009) (Fig. 2E). Our findings suggest that Liprin- $\alpha$ lies at the center of a complex network of interacting proteins (Fig. 2G).

\section{Generating null alleles of Liprin- $\beta$ and Liprin- $\gamma$}

To investigate the functions of Liprin- $\beta$ and Liprin- $\gamma$ in vivo, we generated deletion alleles of these genes. Through imprecise excision of a $\mathrm{P}$ element inserted in the $5^{\prime}$-UTR of Liprin- $\beta, \mathrm{P}\{\mathrm{EP}\} \mathrm{EY} 22999$, we isolated five independent deletions extending into the Liprin- $\beta$ gene (Fig. 3A). Liprin- $\beta^{\Delta 50}$ is a 930 bp deletion, Liprin- $\beta^{\Delta 22}$ and Liprin- $\beta^{\Delta 18}$ are $1.1 \mathrm{~kb}$ deletions, and Liprin- $\beta^{\Delta 51}$ and Liprin- $\beta^{\Delta 83}$ are $1.85 \mathrm{~kb}$ deletions. Liprin- $\beta$ expression was detected throughout the embryo and imaginal discs (Fig. 3C,G). Complete loss of Liprin- $\beta$ transcripts was demonstrated by in situ hybridization for the Liprin- $\beta^{\Delta 51}$ and Liprin- $\beta^{\Delta 83}$ alleles (Fig. $3 E, H$ ), and these alleles were used for subsequent functional experiments.

Since no P element insertions in Liprin- $\gamma$ were available, we made deletions by $\mathrm{X}$-ray mutagenesis, using loss of the white ${ }^{+}$eye color marker on a PiggyBac transposable element insertion in the first intron to identify deletions in the region. Two deletions were 
obtained that when transheterozygous disrupted Liprin- $\gamma$ but not the neighboring genes (Fig. 3B). Liprin- $\gamma$ transcripts were detected specifically in the embryonic and larval nervous system (Fig. 3D and data not shown) and were enriched in the morphogenetic furrow of the eye disc (Fig. 3I, arrowhead). Expression was completely absent in Liprin- $\gamma^{S 1} /$ Liprin- $^{H 1}$ transheterozygotes (Fig. $3 F, J$ ). This allelic combination also disrupts a small gene located within the intron of Liprin- $\gamma$, CG11298. However, CG11298 expression has not been detected in the embryo by the Berkeley Drosophila genome project (www.fruitfly.org), and was found only in the adult testis and larval fat body by FlyAtlas (www.flyatlas.org), making it unlikely to function in the nervous system.

\section{Liprin- $\boldsymbol{\beta}$ promotes $\mathrm{R} 7$ axon \\ termination through Trio}

We first examined the function of Liprin- $\beta$ in R7 photoreceptors, using the reporter construct panR7-lacZ (Hofmeyer et al., 2006) to specifically label their axons. In Liprin- $\alpha$ mutants, R7 axons terminate prematurely in the same target layer as R8 (Choe et al., 2006; Hofmeyer et al., 2006) (Fig. $4 A, B$ ). Liprin- $\beta$ mutants did not show the same phenotype; however, $14-17 \%$ of R7 axons showed projections extending beyond the M6 layer (Fig. 4C,G). This phenotype was not observed in a line carrying a precise excision of the EY22999 P element and was significantly rescued by expression of a UAS-HA-Liprin- $\beta$ transgene in all neurons (Fig. $4 G$ ), confirming that the defect is attributable to loss of Liprin- $\beta$. These results suggest that Liprin- $\beta$ contributes to stabilizing R7 synapses, but in its absence R7 axons continue to grow, rather than remaining in or retracting back to the R8 target layer as they do in Liprin- $\alpha$ mutants. Liprin- $\beta$ appears to act within the R7 photoreceptors, since driving the expression of a hairpin transgene designed to knock down Liprin- $\beta$ by RNAi with sevenless (sev)-GAL4, which is expressed in R7 and a subset of outer photoreceptors, reproduced the overshooting phenotype of Liprin- $\beta$ mutants (Fig. $5 B, F$ ).

In Liprin- $\alpha$ Liprin- $\beta$ double mutants, as in Liprin- $\alpha$ single mutants, many R7 axons terminated prematurely in the M3 layer (Fig. 4D). However, a few R7 axons extended far beyond the M6 layer and even beyond the boundary of the medulla (Fig. 4D; supplemental Fig. S1 $A$, available at www.jneurosci.org as supplemental material). Similarly extended projections were observed in Lar Liprin- $\beta$ double mutants (Fig. 4F; supplemental Fig. $\mathrm{S} 1 B$, available at www. jneurosci.org as supplemental material). This function of Liprin- $\beta$ is also autonomous to R7, since expressing a Liprin- $\beta$ RNAi transgene with sev-GAL4 in a Liprin- $\alpha$ mutant background reproduced
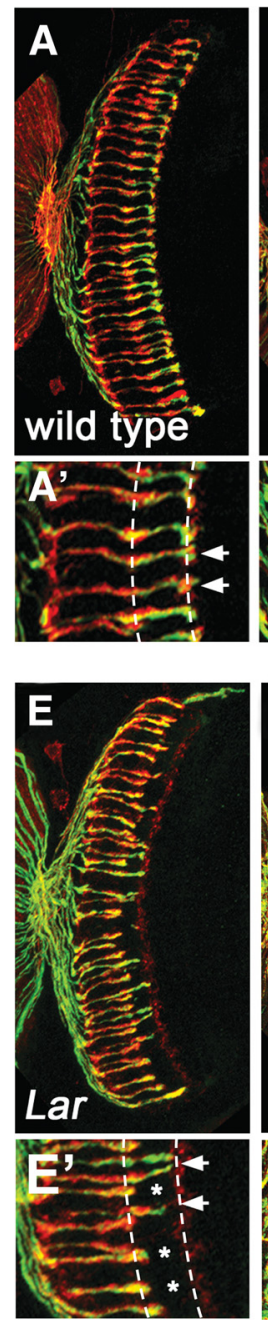
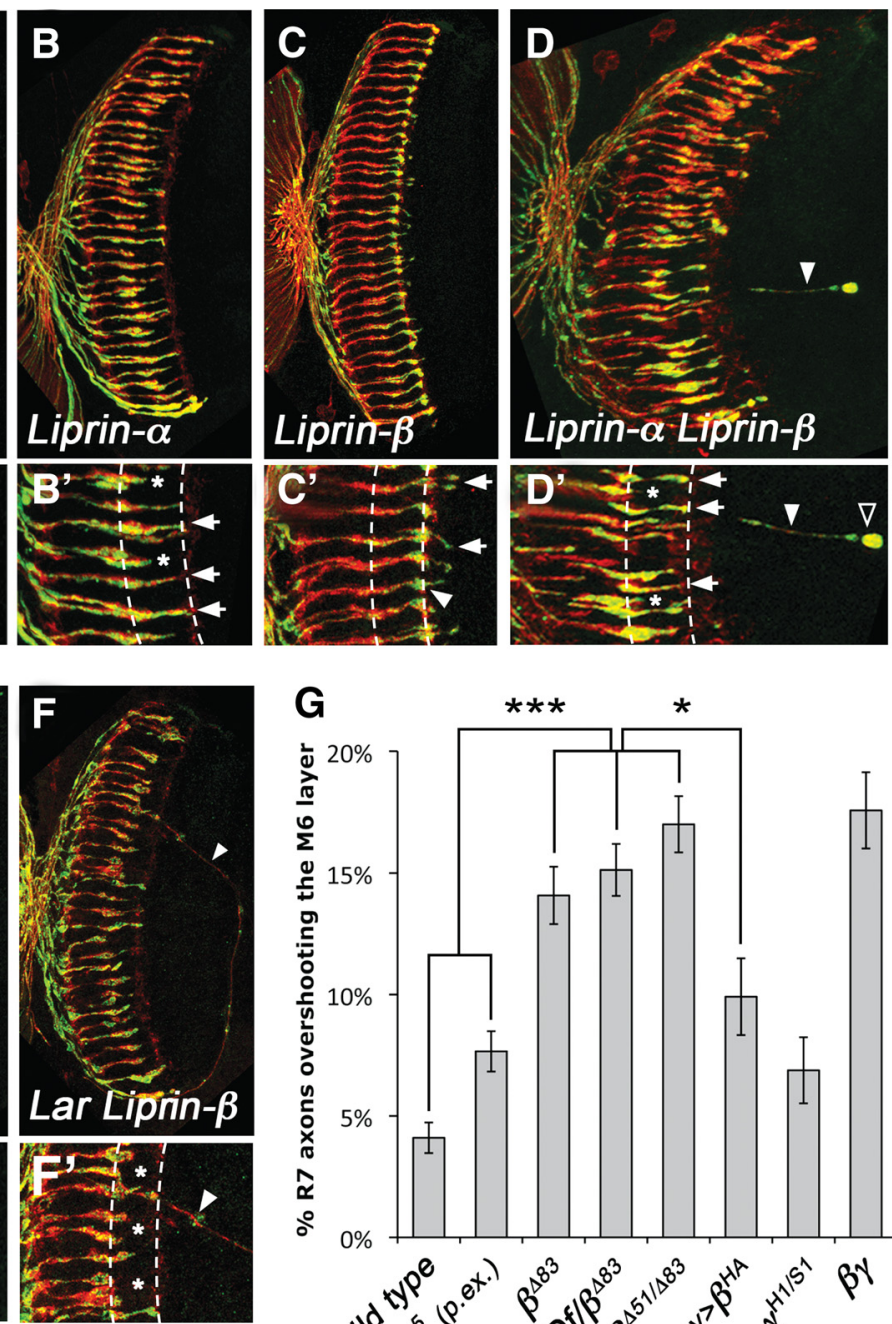

R7 cells Chaoptin

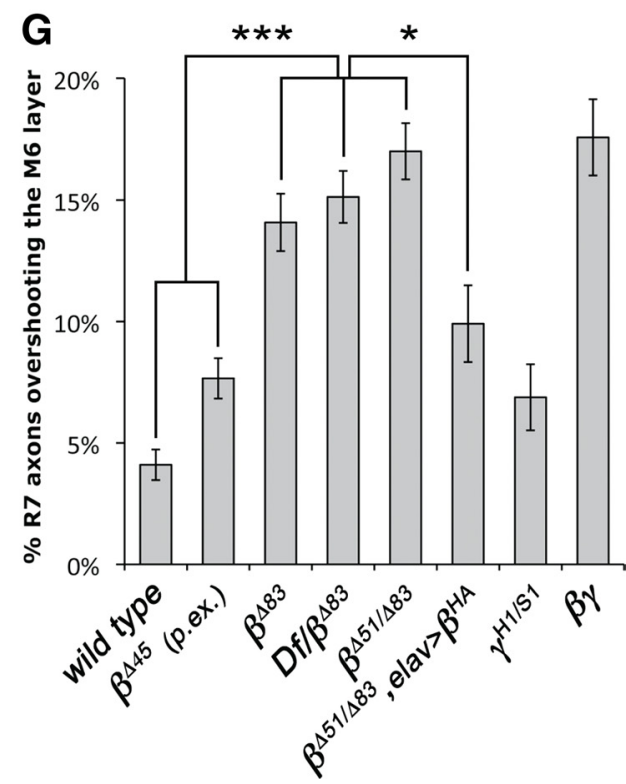

Figure 4. Liprin- $\beta$ contributes to the termination of R7 axon growth in the correct target layer. $\boldsymbol{A}-\boldsymbol{F}$ show head sections of adult flies. R7 and R8 axons are stained with anti-Chaoptin (red) and R7 axons are stained with anti- $\beta$-galactosidase to reveal the expression of panR7-lacZ (green). $\boldsymbol{A}^{\prime}-\boldsymbol{F}^{\prime}$ show enlargements of the medulla neuropil. The M3 and M6 layers are marked by dashed lines (M3, left; M6, right). $\boldsymbol{A}, \boldsymbol{A}^{\prime}$, In wild-type flies, R7 photoreceptors project their axons to the M6 layer in the medulla and form round termini (arrows). $\boldsymbol{B}, \boldsymbol{B}^{\prime}$, In Liprin- $\alpha$ mutants, R7 axons often terminate prematurely in $\mathrm{M} 3$, the R8 target layer (asterisks). Mutant R7 axons that reach the M6 layer usually do not expand their termini (arrows). $C, \boldsymbol{C}^{\prime}$, In Liprin- $\beta$ mutants, some R7 axons extend beyond the M6 layer (arrows), even when the axons have normally expanded termini (arrowheads). $D, D^{\prime}$, Many R7 axons in Liprin- $\alpha$ Liprin- $\beta$ double mutants either do not reach their normal target layer (asterisks) or fail to expand their termini (arrows). Occasional R7 axons project much deeper into the brain (arrowhead), where they can form round termini (empty arrowhead). $\boldsymbol{E}_{,} \boldsymbol{E}^{\prime}$, Lar mutants show a stronger phenotype than Liprin- $\alpha$; the majority of R7 axons stop in the M3 layer (asterisks). $\boldsymbol{F}, \boldsymbol{F}^{\prime}$, In Lar Liprin- $\beta$ double mutants, most R7 axons stop at the M3 layer (asterisks), but some project much further into the brain $\left(\boldsymbol{F}, \boldsymbol{F}^{\prime}\right.$, arrowhead). G, Quantification of the number of R7 axons that project beyond the M6 layer. Liprin- $\beta$ mutants [Liprin- $\beta^{\Delta 83}$ : $14.08 \pm 1.18 \%, 19$ hemispheres (hm); Df(3L)BSC614/Liprin- $\beta^{\Delta 83}: 15.13 \pm 1.07 \%, 15 \mathrm{hm}$; and Liprin- $\beta^{\Delta 51} /$ Liprin- $\beta^{\Delta 83}$ : $17.01 \pm 1.16 \%, 36 \mathrm{hm}$ ] have more protrusions than the controls (wild type: $4.10 \pm 0.63 \%, 14 \mathrm{hm}$; precise excision Liprin- $\beta^{\Delta 45}$ : $7.66 \pm 0.83 \%, 24 \mathrm{hm}$ ). This phenotype is rescued by the expression of a UAS-Liprin- $\beta$ transgene with the pan-neuronal driver elav-GAL4 $(9.91 \pm 1.58 \%, 13 \mathrm{hm})$. Liprin- $\gamma$ mutants $(6.88 \pm 1.36 \%, 10 \mathrm{hm})$ are comparable with the control, and Liprin- $\beta$ Liprin- $\gamma$ double mutants $(17.58 \pm 1.57 \%, 7 \mathrm{hm})$ are similar to Liprin- $\beta$. Error bars represent SEM. ${ }^{*} p<0.05 ;{ }^{* * *} p<0.0001$. the double-mutant phenotype (supplemental Fig. S1C, available at www.jneurosci.org as supplemental material). This novel defect suggests that Liprin- $\beta$ can contribute to target recognition or synapse stability independently of Liprin- $\alpha$ and LAR.

Trio, a guanine nucleotide exchange factor for Rac, is thought to act as an effector of LAR in R7 and in other contexts (Debant et al., 1996; Bateman et al., 2000; Maurel-Zaffran et al., 


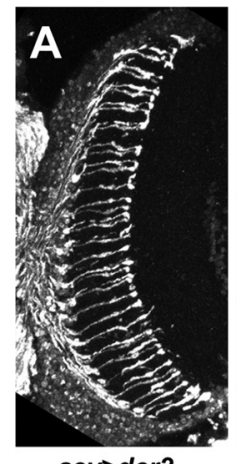

sev>dcr2



BRNAi, dcr2

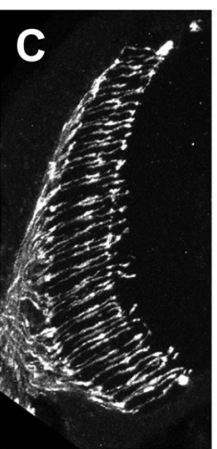

sev>

trioRNAi, dcr2

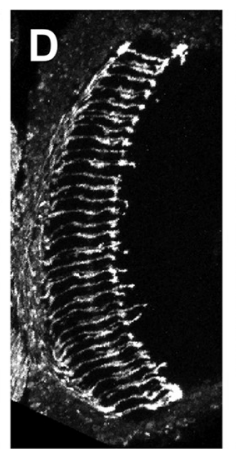

Liprin- $\beta$

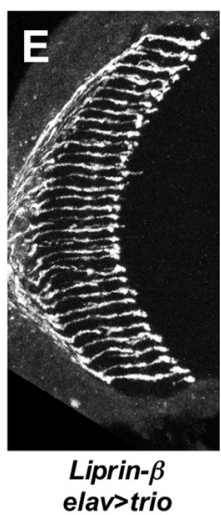

$\mathbf{F}$

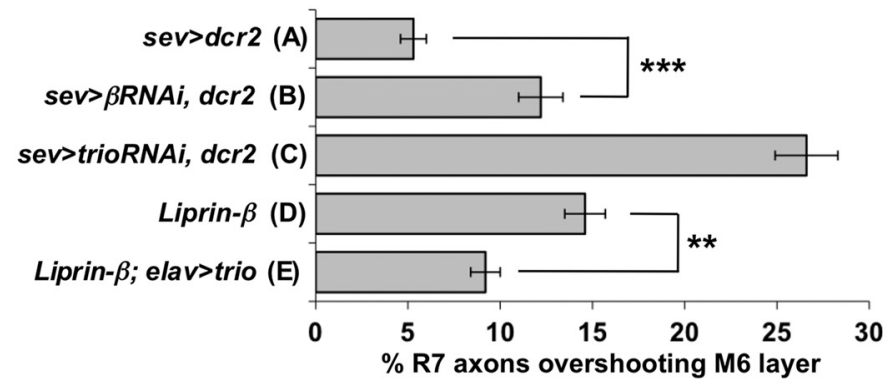

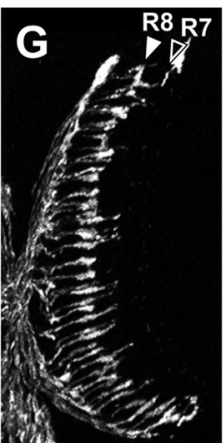

Liprin- $\alpha$

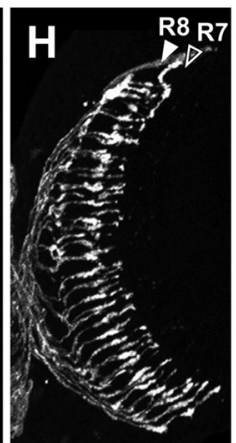

Liprin- $\alpha$

GMR>trio
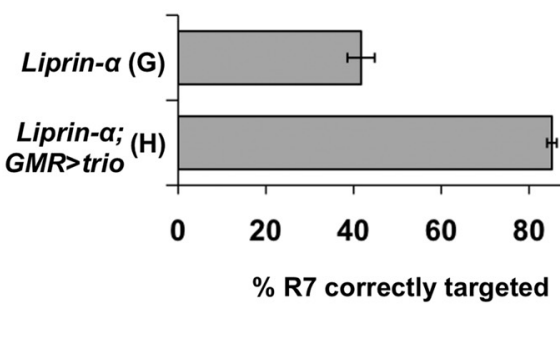

$0 \quad 20$
2040

$\%$ R7 correctly targeted

Figure 5. Trio acts downstream of Liprin- $\beta$ and Liprin- $\alpha$ in R7 targeting. $\boldsymbol{A}-\boldsymbol{E}$ show adult head sections stained with anti- $\beta$ galactosidase to reveal glass-lacZ expression. A, UAS-dcr2/Cy0; sev-GAL4/TM6c (control). B, UAS-dcr2/+; sev-GAL4/UAS-Liprin- $\beta$ RNAi. C, UAS-dcr2/+; sev-GAL4/UAS-trio RNAi. D, Liprin- $\beta^{\Delta 51}$. E, elav-trio/Cy0; Liprin- $\beta^{\Delta 51}$. $\boldsymbol{F}$ shows a quantification of the percentage of axons projecting beyond the M6 layer in each genotype. Expression of trio RNAi causes overshooting of the R7 target layer $(26.6 \pm 1.7 \%, 17 \mathrm{hm})$ similar to Liprin- $\beta$ mutants $(14.6 \pm 1.1 \%, 18 \mathrm{hm})$ or expression of Liprin- $\beta$ RNAi in R7 $(12.2 \pm 1.2 \%$, $18 \mathrm{hm}) .0$ verexpression of Trio in a Liprin- $\beta$ mutant background rescues the phenotype $(9.2 \pm 0.8 \%, 19 \mathrm{hm}) . \boldsymbol{G}$ and $\boldsymbol{H}$ show adult head sections stained with anti- $\beta$-galactosidase to reveal glass-lacZ expression. G, Liprin- $\alpha^{\text {oos }}$. H, Liprin- $\alpha^{\text {oos }}$; GMR-trio. I shows a quantification of the percentage of axons projecting beyond the M3 layer in each genotype. Overexpression of Trio in a Liprin- $\alpha$ mutant background rescues the early termination of $\mathrm{R} 7$ axons $(85.2 \pm 1.1 \% \mathrm{R} 7$ axons correctly targeted, $18 \mathrm{hm}, 907 \mathrm{cl}$, compared with $41.7+3.1 \%, 10 \mathrm{hm}, 646 \mathrm{cl}$ for Liprin- $\alpha$ alone). cl, Columns (pairs of R7-R8). The arrows indicate the R7 and R8 target layers. Error bars represent SEM. ${ }^{* *} p<0.001 ;{ }^{* * *} p<0.0001$.

2001; Pawson et al., 2008). To confirm a role of Trio in the LAR/Liprin- $\alpha$ pathway, we tested whether Trio overexpression could compensate for the loss of Liprin- $\alpha$. Indeed, the premature termination of R7 axons was strongly rescued in Liprin- $\alpha$ mutants expressing Trio in all photoreceptors (Fig. $5 G-I)$. Interestingly, reducing the function of Trio in R7 by expressing an RNAi transgene with sev-GAL4 resulted in growth of R7 axons beyond the M6 layer, as in Liprin- $\beta$ mutants (Fig. 5C,F). Pan-neuronal overexpression of Trio also rescued the overgrowth of R7 axons in Liprin- $\beta$ mutants (Fig. $5 D-F$ ), indicating that Trio integrates input from both Liprin- $\alpha$ and Liprin- $\beta$.
Liprin- $\beta$ is required for NMJ growth Another well characterized function of Liprin- $\alpha$ and Lar is in mediating growth of the larval NMJ (Kaufmann et al., 2002). We therefore tested whether Liprin- $\beta$ had a function in this context as well. We found that Liprin- $\beta$ mutants also showed reduced NMJ size; the numbers of synaptic boutons at the muscle 6/7 synapses in abdominal segments A2 and A 3 were very similar to the numbers in Liprin- $\alpha$ mutants, and $\sim 70 \%$ of the numbers present in synapses from larvae homozygous for a precise excision of the EY22999 element (Fig. 6A-C,I; supplemental Fig. S2, available at www.jneurosci.org as supplemental material). Liprin- $\beta$ is likely to affect bouton formation rather than maintenance, since Liprin- $\beta$ mutants showed no sites at which postsynaptic Dlg was not apposed to presynaptic Syt (supplemental Fig. S3A-D, available at www.jneurosci. org as supplemental material); such "footprints" left on the muscle cell would result from disassembly after initial synapse formation (Eaton et al., 2002). The distribution of the presynaptic marker Brp (Wagh et al., 2006) and the postsynaptic marker GluRIIA (glutamate receptor IIA) (Saitoe et al., 1997) also appeared normal in Liprin- $\beta$ mutants (supplemental Fig. $\mathrm{S} 3 E-H$, available at www.jneurosci.org as supplemental material).

Interestingly, Liprin- $\alpha$ Liprin- $\beta$ double mutants showed an additional $25-30 \%$ decrease in bouton number compared with either single mutant (Fig. 6E, I; supplemental Fig. S2, available at www.jneurosci.org as supplemental material), suggesting that the two Liprins make independent contributions to the expansion of neuromuscular synapses. The conclusion that Liprin- $\alpha$ and Liprin- $\beta$ act in parallel on the same processes is further strengthened by our observation that the viability of Liprin- $\alpha$ Liprin- $\beta$ double mutants ( $4 \%$ of the expected number survived to adulthood; $n=257$ ) was reduced compared with Liprin- $\alpha$ single mutants ( $19 \%$ of the expected number; $n=$ 294) and Liprin- $\beta$ single mutants ( $86 \%$ of the expected number; $n=368$ ).

Lar acts in the motor neurons to promote synapse growth, but the location of Liprin- $\alpha$ function has not been defined (Kaufmann et al., 2002). We tested whether NMJ size in Liprin- $\beta$ mutants could be rescued by expressing wild-type Liprin- $\beta$ either in neurons, with elav ${ }^{C 155}$-GAL4, or in muscles, using how ${ }^{24 B}$-GAL4. We observed that restoring the expression of Liprin- $\beta$ in either neurons or muscle cells restored the number of boutons to the level of the precise excision (Fig. 6I; supplemental Fig. S2, available at www.jneurosci.org as supplemental material), indicating that Liprin- $\beta$ can act either presynaptically or postsynaptically to promote synapse growth. Because trio is also required for NMJ size regulation (Pawson et al., 2008; Ball et al., 2010), we tested 
whether it might also mediate Liprin function in this context. We found that expression of UAS-trio in either neurons or muscles could restore normal synapse size to Liprin- $\beta$ mutants (Fig. 6I; supplemental Fig. S2, available at www.jneurosci.org as supplemental material). Trio expression in neurons was also sufficient to rescue the NMJ phenotype of Liprin- $\alpha$ mutants (Fig. 6I; supplemental Fig. S2, available at www. jneurosci.org as supplemental material); we could not test the effect of muscle-specific Trio expression in these mutants because of early lethality of this genetic combination.

Liprin- $\gamma$ antagonizes the functions of the other two Liprins

We found that Liprin- $\gamma$ mutants showed no obvious defects in either the R7 projection pattern, or the size of larval NMJs (Figs. $6 D, I, 7 A, D$; supplemental Fig. S2, available at www.jneurosci.org as supplemental material). However, removing Liprin- $\gamma$ in the absence of Liprin- $\alpha$ or Liprin- $\beta$ revealed antagonistic functions for this Liprin. At the NMJ, Liprin- $\alpha$ Liprin- $\gamma$ double mutants were not significantly different from Liprin- $\alpha$ single mutants (Fig. 6F, I; supplemental Fig. S2, available at www.jneurosci.org as supplemental material), but Liprin- $\beta$ Liprin- $\gamma$ double mutants formed more synaptic boutons than Liprin- $\beta$ single mutants, resembling Liprin- $\gamma$ single mutants or controls (Fig. 6G,I; supplemental Fig. S2, available at www.jneurosci.org as supplemental material). In addition, Liprin- $\alpha$ Liprin- $\beta$ Liprin- $\gamma$ triple-mutant synapses were larger than Liprin- $\alpha$ Liprin- $\beta$ double mutants, and approximately the same size as Liprin- $\alpha$ single mutants (Fig. $6 H$, I; supplemental Fig. S2, available at www.jneurosci.org as supplemental material). Liprin- $\gamma$ thus appears to counteract the function of Liprin- $\beta$ in NMJ growth.

In R7 photoreceptors, Liprin- $\gamma$ showed genetic interactions with Liprin- $\alpha$ rather than Liprin- $\beta$. Liprin- $\alpha$ Liprin- $\gamma$ double mutants showed significantly improved R7 targeting compared with Liprin- $\alpha$ single mutants (Fig. $7 B, D$ ). Liprin- $\alpha$ Liprin- $\gamma$ double mutants also showed increased viability $(43 \%$ of the expected number; $n=$ 656) compared with Liprin- $\alpha$ single mutants $(22 \%$ of the expected number; $n=297$ ), and double-mutant males were fertile, whereas Liprin- $\alpha$ single-mutant males were sterile. This suggests that wildtype Liprin- $\alpha$ may keep in check activities of Liprin- $\gamma$ that have a negative impact on survival, male fertility, and R7 synapse stability. Loss of Liprin- $\gamma$ did not rescue R7 targeting in Lar mutants (Fig. 7C,D), indicating that LAR is essential for this process even in the absence of Liprin- $\gamma$. Similarly, loss of Liprin- $\gamma$ did not
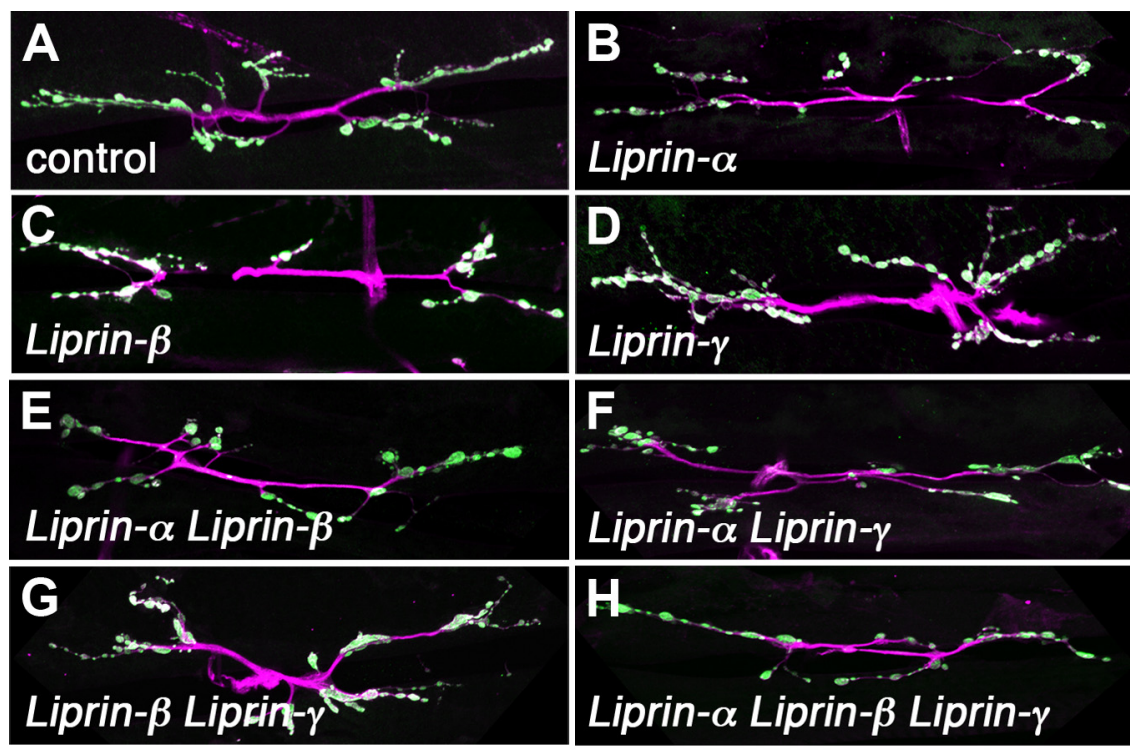

Abdominal Segment 2 - NMJ 6/7

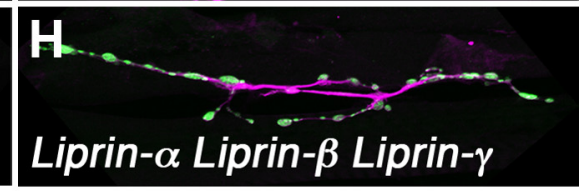

Syt HRP
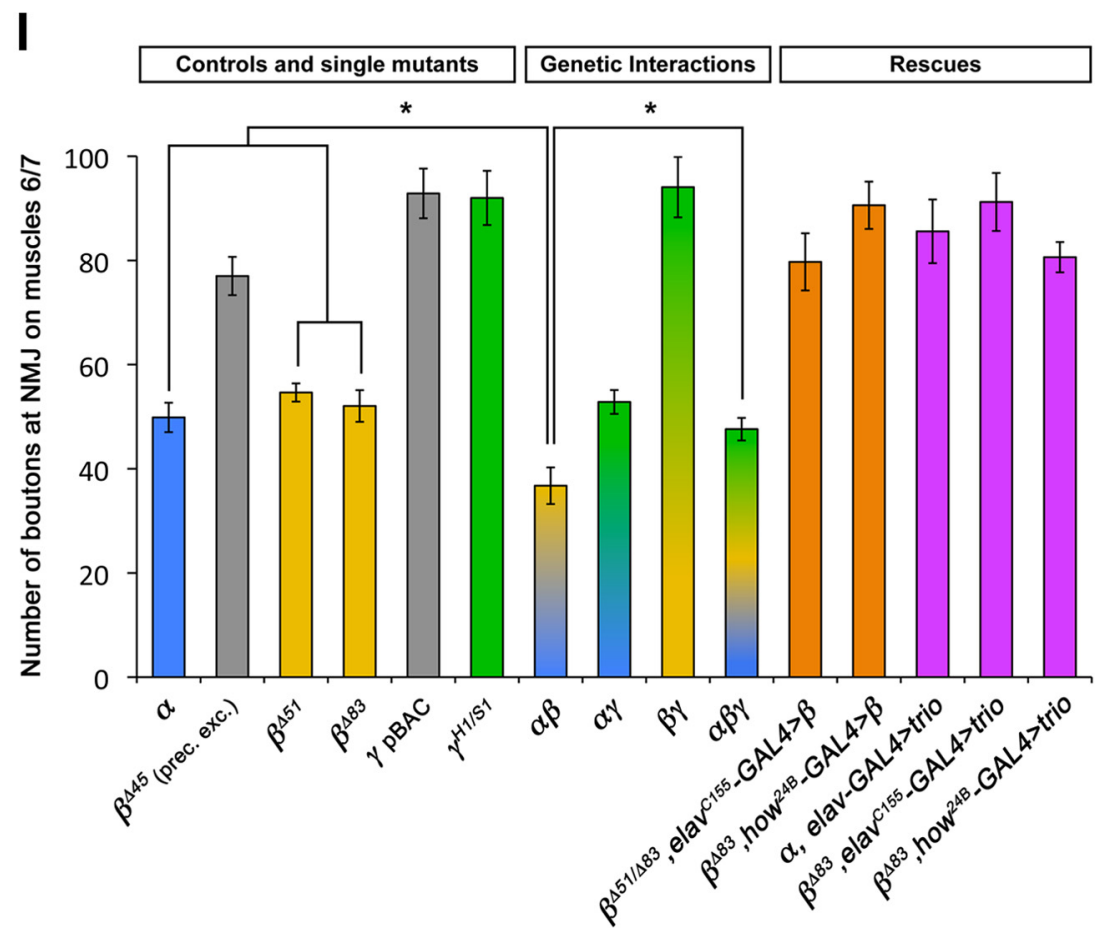

Figure 6. Neuromuscular synapse size is reduced in Liprin- $\beta$ mutants. $\boldsymbol{A}-\boldsymbol{H}$ show synapses formed on muscles 6 and 7 in abdominal segment 2 (A2) of third-instar larvae. Nerves are stained with anti-HRP (magenta) and synaptic boutons with antiSynaptotagmin (green). $A$, Control synapse from $p B A C f 01268$, the line in which Liprin- $\gamma$ mutations were generated. $B$, Liprin- $\alpha$ oos.

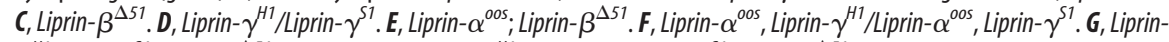
$\gamma^{H 1} /$ Liprin- $\gamma^{51}$; Liprin- $\beta^{\Delta 51}$. H, Liprin- $\alpha^{\text {oos }}$, Liprin- $\gamma^{H 1} /$ Liprin- $\alpha^{\text {oos }}$, Liprin- $\gamma^{51}$; Liprin- $\beta^{\Delta 51}$. I, Quantification of the number of boutons in abdominal segment 2 for the genotypes indicated. The precise excision line $\Delta 45$ was used as a control for Liprin- $\beta$, and pBACf01268, which does not affect Liprin- $\gamma$ expression, was used as a control for Liprin- $\gamma$. Liprin- $\alpha$ and Liprin- $\beta$ mutants have fewer boutons than controls, and the Liprin- $\alpha$ Liprin- $\beta$ double-mutant synapse is even smaller. Liprin- $\gamma$ single mutants have normally sized synapses and removal of Liprin- $\gamma$ does not affect Liprin- $\alpha$ mutants. However, removal of Liprin- $\gamma$ increases the number of boutons at Liprin- $\beta$ or Liprin- $\alpha$ Liprin- $\beta$ mutant synapses. Liprin- $\alpha$ is rescued by expressing UAS-trio in neurons using elav ${ }^{1155}$-GAL4. Liprin- $\beta$ is rescued by expressing UAS-Liprin- $\beta$ or UAS-trio either in neurons, using elav ${ }^{\text {C155 }}$-GAL4, or in muscles, using how ${ }^{24 B}$-GAL4. Between 14 and 23 NMJs were analyzed for each genotype. Error bars represent SEM. ${ }^{*} p<0.05$.

rescue the sterility of Lar mutant females. Removing Liprin- $\gamma$ also did not alter the proportion of Liprin- $\beta$ mutant R7 cells with projections extending beyond the M6 layer (Fig. 4G; supplemental Fig. S1D, available at www.jneurosci.org as supplemental material). 

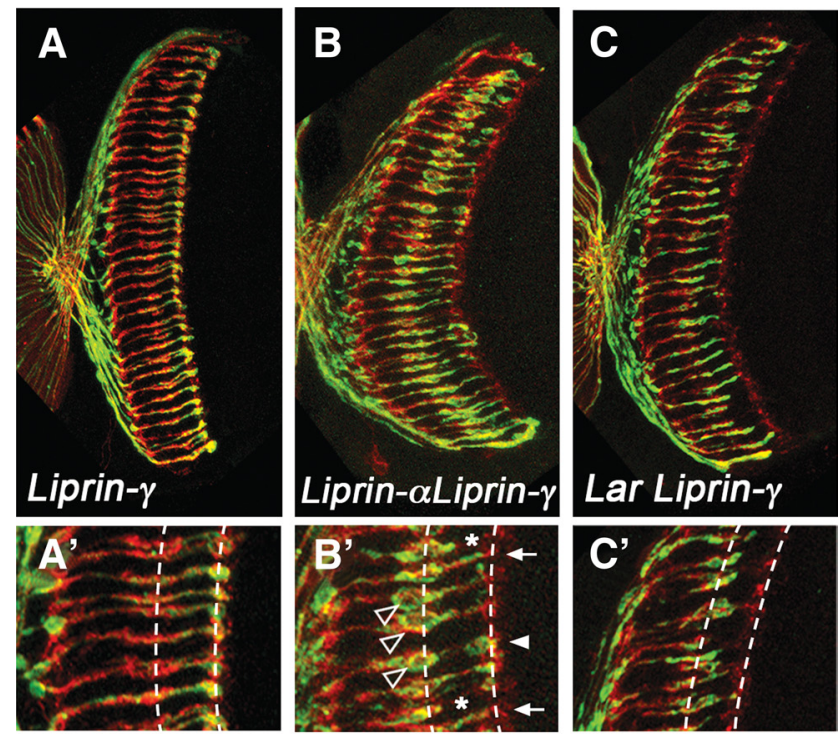

R7 cells Chaoptin
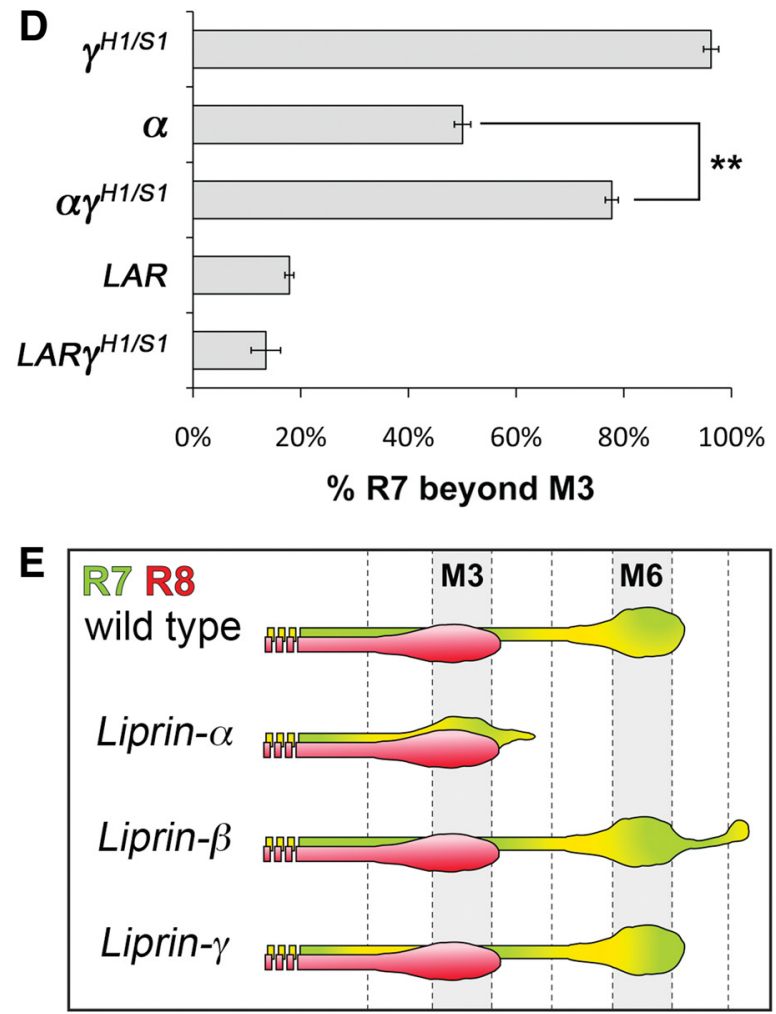

Figure 7. Liprin- $\gamma$ antagonizes Liprin- $\alpha$ in R7 targeting. $\boldsymbol{A}-\boldsymbol{C}$ show adult head sections stained with anti-Chaoptin (red) and anti- $\beta$-galactosidase to reveal the expression of panR7-lacZ (green). Regions of the medulla neuropil are enlarged in $\boldsymbol{A}^{\prime}-\boldsymbol{C}^{\prime} . \boldsymbol{A}_{\boldsymbol{1}} \boldsymbol{A}^{\prime}$, Liprin- $\gamma$ mutants show normal R7 targeting. $\boldsymbol{B}, \boldsymbol{B}^{\prime}$, Liprin- $\alpha$ Liprin- $\gamma$ double mutants. More R7 axons reach the M6 layer than in Liprin- $\alpha$ single mutants. Interestingly, some R7 axons expand in the $\mathrm{M} 3$ layer (empty arrowheads), although they also form round termini in the M6 layer (arrowhead). $\mathbf{C}, \boldsymbol{C}^{\prime}$, Lar Liprin- $\gamma$ double mutants are similar to Lar single mutants. $\boldsymbol{E}$ shows a quantification of the percentage of $\mathrm{R} 7$ axons projecting beyond the $\mathrm{M} 3$ layer in the indicated genotypes. The Liprin- $\alpha$ phenotype $(50.06 \% \pm 1.52 \%, 21 \mathrm{hm}, 1605$ cl) is improved when Liprin- $\gamma$ is removed in this background $(77.77 \pm 1.20 \%, 16 \mathrm{hm}$, $1588 \mathrm{cl}$ ), suggesting an antagonistic relationship between Liprin- $\alpha$ and Liprin- $\gamma$. However, the Lar phenotype $(17.90 \pm 0.82 \%, 15 \mathrm{hm}, 1872 \mathrm{cl})$ is not rescued in Lar Liprin- $\gamma$ double mutants $(13.52 \pm 2.74 \%, 9 \mathrm{hm}, 533 \mathrm{cl}$ ). $\boldsymbol{E}$ shows a diagram of the R7 phenotypes of the three Liprin mutants. Error bars represent SEM. ${ }^{* *} p<0.001$.
The deleterious effects of Liprin- $\gamma$ in the absence of Liprin- $\alpha$ might be attributable to its interactions with LAR. This would imply that, in the wild-type situation, little Liprin- $\gamma$ is bound to LAR because of the stronger binding of Liprin- $\alpha$. To investigate this possibility, we tested whether Liprin- $\gamma$ could compete with Liprin- $\alpha$ for LAR binding. We first deleted the $\mathrm{N}$ terminus of Liprin- $\gamma$ to generate a form that could coimmunoprecipitate LAR but not Liprin- $\alpha$ (Liprin- $\gamma \Delta \mathrm{N}$ ) (Fig. $8 A, B$ ). As a control, we showed that Liprin- $\gamma \Delta \mathrm{N}$ could compete with full-length Liprin- $\gamma$ for LAR binding, whereas Liprin- $\gamma \Delta \mathrm{C}$, which does not bind LAR (Fig. 2D), could not (Fig. 8C). However, the presence of Liprin- $\gamma \Delta \mathrm{N}$ did not reduce the binding of Liprin- $\alpha$ to LAR (Fig. $8 C$ ), indicating that LAR interacts more strongly with Liprin- $\alpha$ than with Liprin- $\gamma$.

\section{Discussion}

We have shown that the Liprin family in Drosophila consists of three proteins that interact both physically and functionally. Liprin- $\beta$, like Liprin- $\alpha$, is required for normal synapse formation by both R7 photoreceptors and larval motor neurons. In contrast, Liprin- $\gamma$ appears to oppose the functions of the other two Liprins. These cooperative and antagonistic interactions could be based on the ability of both Liprin- $\beta$ and Liprin- $\gamma$ to bind to Liprin- $\alpha$, and of both Liprin- $\alpha$ and Liprin- $\gamma$ to bind to LAR. Our observations suggest that the relative levels of the three Liprins determine the functional state of scaffolding networks involved in synapse assembly.

\section{Liprin- $\alpha$ and Liprin- $\beta$ have synergistic functions in synaptogenesis}

Liprin- $\beta$ function is required at two classes of synapses previously shown to require Liprin- $\alpha$ : the synapses formed by R7 photoreceptors on their target neurons in the medulla (Choe et al., 2006; Hofmeyer et al., 2006), and the synapses formed by larval motor neurons on their target muscles (Kaufmann et al., 2002). In R7, both Liprins appear to act presynaptically (Hofmeyer et al., 2006) (Fig. $5 B, F$ ), but their loss has different consequences (Fig. 7E). Liprin- $\alpha$ mutant $\mathrm{R} 7$ cells terminate in $\mathrm{M} 3$, the R8 target layer, in the adult, although they correctly reach the R7 temporary target layer early in pupal development (Hofmeyer et al., 2006). This suggests that they fail to form stable connections with the appropriate target neurons, and either remain in their temporary layer or retract back to it. In Liprin- $\beta$ mutants, R7 axons reach their final M6 target layer, but a subset then project beyond it, suggesting that Liprin- $\beta$ is needed to terminate axon growth in response to target recognition. R7 axons can grow far beyond the M6 layer in Liprin- $\alpha$ Liprin- $\beta$ double mutants, consistent with a partially redundant role for both proteins in this process. Liprin- $\alpha$ and Liprin- $\beta$ might stabilize R7 terminals through two different mechanisms. Alternatively, Liprin- $\beta$ might make a more minor contribution than Liprin- $\alpha$ or function at a later developmental stage, such that in Liprin- $\beta$ mutants the axon terminal forms in the correct layer, but axonal branches are destabilized. The similar phenotype of trio knockdown in R7 and the ability of Trio overexpression to rescue R7 targeting in Liprin- $\alpha$, Liprin- $\beta$, and Lar mutants (Maurel-Zaffran et al., 2001) (Fig. 5) support a model in which both Liprins and LAR act upstream of Trio (Fig. $8 D$ ). The presence of separate Rac and Rho guanine nucleotide exchange factor domains in Trio (Newsome et al., 2000) raises the possibility that it can perform independent functions induced by these different inputs.

At the larval NMJ, Liprin- $\alpha$ and Liprin- $\beta$ mutants both reduce synapse size to an equivalent extent, and the double mutant 
shows an additional decrease in size, indicating that the two Liprins have independent activities (Fig. $8 F$ ). Syndecan, LAR, and Liprin- $\alpha$ appear to act together to promote NMJ growth (Kaufmann et al., 2002; Johnson et al., 2006) by regulating the formin Diaphanous, perhaps through Trio (Pawson et al., 2008) (Fig. 5G-I). Lar function is limited to the presynaptic side of the NMJ (Kaufmann et al., 2002). Although Liprin- $\alpha$ is present on both sides of the synapse (Kaufmann et al., 2002), it contributes to the presynaptic but not postsynaptic functions of its regulator Dsyd-1 (Owald et al., 2010). In contrast, we find that Liprin- $\beta$ can act in either motor neurons or muscles to promote synapse growth. Although a previous study showed that trio mutants were rescued by Trio expression in neurons but not in muscles (Ball et al., 2010), we found that Trio expression in either cell type could rescue Liprin- $\beta$ mutants. These results suggest that Liprin- $\beta$ acts via Trio and/or another GEF to stabilize both presynaptic and postsynaptic structures, and that communication between the two sides of the synapse enables one to promote the formation of the other. Alternatively, Liprin- $\beta$ might directly interact with proteins that mediate this transsynaptic communication. The secreted BMP (bone morphogenetic protein) family member Glass bottom boat and its receptors Wishful thinking and Saxophone (Aberle et al., 2002; McCabe et al., 2003; Rawson et al., 2003), as well as the signaling molecules Wingless and Wnt5 (Packard et al., 2002; Liebl et al., 2008), are known to contribute to NMJ growth and might be affected by the loss of Liprin- $\beta$.

\section{Liprin- $\gamma$ functionally antagonizes the other two Liprins}

Liprin- $\gamma$ shares both structural organization and sequence homology with Liprin- $\alpha$ and Liprin- $\beta$, suggesting that it is a member of the same protein family. We show here that its expression is specific to the nervous system, in contrast to the ubiquitous expression of human KazrinE (Nachat et al., 2009), and that it exhibits both physical and genetic interactions with the other two Liprins. Interestingly, it is not essential for the formation of either photoreceptor or neuromuscular synapses, but appears to negatively regulate the expansion or stability of these synapses in a manner that is only apparent in the absence of one of the other Liprins. The presence of Liprin- $\gamma$ contributes to the failure of R7 targeting seen in Liprin- $\alpha$ mutants, since removing Liprin- $\gamma$ improves the Liprin- $\alpha$ phenotype (Fig. 7B,D). At the NMJ, loss of Liprin- $\beta$ causes a size reduction only in the presence of Liprin- $\gamma$, indicating that the primary function of Liprin- $\beta$ in this context is to counteract the activity of Liprin- $\gamma$.

The biochemical mechanisms leading to these antagonistic relationships are currently unknown. Liprin- $\beta$ and Liprin- $\gamma$ have no homology to known catalytic domains, although the LHD of Liprin- $\alpha$ has been reported to have kinase activity (Serra-Pagès et al., 2005). They are therefore most likely to act by binding to other
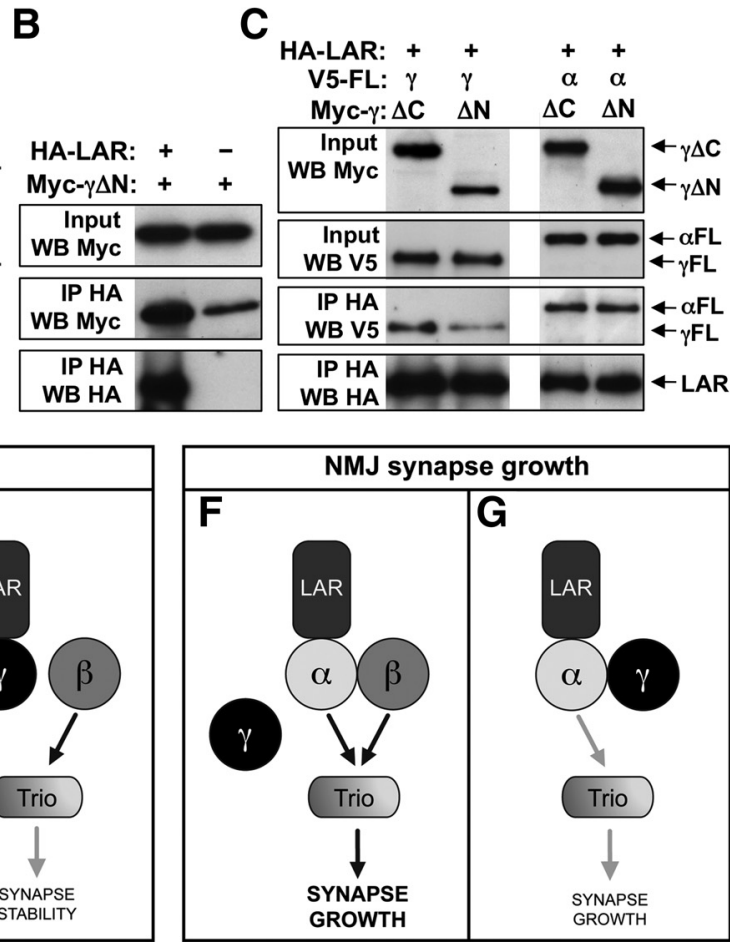

Figure 8. Competitive interactions between Liprins and LAR. A-C show coimmunoprecipitations of epitope-tagged proteins expressed in $S 2 \mathrm{R}^{+}$cells. $\boldsymbol{A}$, Full-length HA-tagged Liprin- $\alpha$ is pulled down with Myc-tagged Liprin- $\gamma \Delta \mathrm{C}$ or Liprin- $\gamma \Delta \mathrm{N}$ by . Antibody heavy chain. $B$, Myc-tagged Liprin- $\gamma \Delta$ N is pulled down with HA-tagged LAR by immunoprecipitation with M 列 列


Liprin- $\alpha$ in the absence of Liprin- $\beta$, contributing to the lack of synapse growth in Liprin- $\beta$ mutants.

molecules, although few binding partners have yet been characterized. Human Liprin- $\beta 1$ interacts with S100A4, a protein involved in motility of metastatic cells (Kriajevska et al., 2002), and its second SAM domain is predicted to form a homopolymer (Meruelo and Bowie, 2009), suggesting that it could assemble a large scaffolding structure. KazrinE has been shown to bind to the desomosomal protein Periplakin and to stable acetylated microtubules (Groot et al., 2004; Nachat et al., 2009). Liprin- $\gamma$ might compete with the other two Liprins for interactions with specific binding partners. For example, we have shown that Liprin- $\alpha$ and Liprin- $\gamma$ can both bind to LAR; however, the interaction with Liprin- $\alpha$ appears stronger, since Liprin- $\alpha$ binding to LAR was not reduced in the presence of Liprin- $\gamma$ (Fig. $8 C$ ). This suggests that competition for LAR might be the mechanism for their antagonistic interaction in R7 targeting (Fig. $8 D, E)$. In addition, Liprin- $\beta$ and Liprin- $\gamma$ can both bind to Liprin- $\alpha$. It is possible that interactions with Liprin- $\beta$ promote the normal localization or function of Liprin- $\alpha$ at the NMJ, whereas in the absence of Liprin- $\beta$, Liprin- $\alpha$ undergoes nonproductive interactions with Liprin- $\gamma$ (Fig. $8 F, G$ ).

The ability of Liprins to bind distinct partners through their $\mathrm{N}$ - and C-terminal domains (Serra-Pagès et al., 1998; Schoch et al., 2002; Wyszynski et al., 2002; Ko et al., 2003a,b; Shin et al., 
2003; Olsen et al., 2005; Nachat et al., 2009) would allow them to assemble complex networks; the presence of Liprin- $\gamma$ may alter the structure, composition, or subcellular localization of these networks. Its negative effects on the R7 and neuromuscular synapses suggest that Liprin- $\gamma$ could be involved in the homeostatic processes that adjust synapse size or function, either during development or in response to environmental changes (Stewart et al., 1996; van Roessel et al., 2004; Yoshihara et al., 2005; Frank et al., 2006; Gilestro et al., 2009).

\section{Different modes of Liprin function at photoreceptor and motor neuron synapses}

One surprising feature of our findings is that the three Liprins show different interactions at the two synapses we examined. At the NMJ, Liprin- $\alpha$ and Liprin- $\beta$ have indistinguishable mutant phenotypes but removing Liprin- $\gamma$ affects only Liprin- $\beta$ mutants, whereas in R7 Liprin- $\alpha$ and Liprin- $\beta$ have distinct phenotypes and removing Liprin- $\gamma$ affects only Liprin- $\alpha$ mutants. These differences are likely to reflect different Liprin structural organizations or binding partners. Similarly, we have found that LAR uses distinct ligands and signaling mechanisms at these two synapses (Hofmeyer and Treisman, 2009). R7 targeting, which involves forming numerous synapses on multiple postsynaptic cells at approximately the same developmental stage (Gao et al., 2008; Morante and Desplan, 2008; Takemura et al., 2008), may be controlled differently from increases in the number of synaptic boutons formed by motor neurons during larval life to match the growth of their target muscles (Collins and DiAntonio, 2007). Alternatively, sensory and motor synapses may use distinct assembly mechanisms. Although the NMJ is an accessible and very well studied synapse, it is unlikely that its mode of development can be fully generalized to sensory or central synapses.

\section{References}

Aberle H, Haghighi AP, Fetter RD, McCabe BD, Magalhães TR, Goodman CS (2002) wishful thinking encodes a BMP type II receptor that regulates synaptic growth in Drosophila. Neuron 33:545-558.

Ball RW, Warren-Paquin M, Tsurudome K, Liao EH, Elazzouzi F, Cavanagh C, An BS, Wang TT, White JH, Haghighi AP (2010) Retrograde BMP signaling controls synaptic growth at the NMJ by regulating Trio expression in motor neurons. Neuron 66:536-549.

Bateman J, Shu H, Van Vactor D (2000) The guanine nucleotide exchange factor trio mediates axonal development in the Drosophila embryo. Neuron 26:93-106.

Biederer T, Stagi M (2008) Signaling by synaptogenic molecules. Curr Opin Neurobiol 18:261-269.

Choe KM, Prakash S, Bright A, Clandinin TR (2006) Liprin- $\alpha$ is required for photoreceptor target selection in Drosophila. Proc Natl Acad Sci U S A 103:11601-11606.

Clandinin TR, Lee CH, Herman T, Lee RC, Yang AY, Ovasapyan S, Zipursky SL (2001) Drosophila LAR regulates R1-R6 and R7 target specificity in the visual system. Neuron 32:237-248.

Collins CA, DiAntonio A (2007) Synaptic development: insights from Drosophila. Curr Opin Neurobiol 17:35-42.

Dai Y, Taru H, Deken SL, Grill B, Ackley B, Nonet ML, Jin Y (2006) SYD-2 Liprin-alpha organizes presynaptic active zone formation through ELKS. Nat Neurosci 9:1479-1487.

Debant A, Serra-Pagès C, Seipel K, O'Brien S, Tang M, Park SH, Streuli M (1996) The multidomain protein Trio binds the LAR transmembrane tyrosine phosphatase, contains a protein kinase domain, and has separate rac- specific and rho-specific guanine nucleotide exchange factor domains. Proc Natl Acad Sci U S A 93:5466-5471.

Dickinson BA, Jo J, Seok H, Son GH, Whitcomb DJ, Davies CH, Sheng M, Collingridge GL, Cho K (2009) A novel mechanism of hippocampal LTD involving muscarinic receptor-triggered interactions between AMPARs, GRIP and liprin-alpha. Mol Brain 2:18.

Dietzl G, Chen D, Schnorrer F, Su KC, Barinova Y, Fellner M, Gasser B,
Kinsey K, Oppel S, Scheiblauer S, Couto A, Marra V, Keleman K, Dickson BJ (2007) A genome-wide transgenic RNAi library for conditional gene inactivation in Drosophila. Nature 448:151-156.

Eaton BA, Fetter RD, Davis GW (2002) Dynactin is necessary for synapse stabilization. Neuron 34:729-741.

Frank CA, Kennedy MJ, Goold CP, Marek KW, Davis GW (2006) Mechanisms underlying the rapid induction and sustained expression of synaptic homeostasis. Neuron 52:663-677.

Gao S, Takemura SY, Ting CY, Huang S, Lu Z, Luan H, Rister J, Thum AS, Yang M, Hong ST, Wang JW, Odenwald WF, White BH, Meinertzhagen IA, Lee CH (2008) The neural substrate of spectral preference in Drosophila. Neuron 60:328-342.

Gilestro GF, Tononi G, Cirelli C (2009) Widespread changes in synaptic markers as a function of sleep and wakefulness in Drosophila. Science 324:109-112.

Groot KR, Sevilla LM, Nishi K, DiColandrea T, Watt FM (2004) Kazrin, a novel periplakin-interacting protein associated with desmosomes and the keratinocyte plasma membrane. J Cell Biol 166:653-659.

Hofmeyer K, Treisman JE (2009) The receptor protein tyrosine phosphatase LAR promotes R7 photoreceptor axon targeting by a phosphatase-independent signaling mechanism. Proc Natl Acad Sci U S A 106:19399-19404.

Hofmeyer K, Maurel-Zaffran C, Sink H, Treisman JE (2006) Liprin- $\alpha$ has LAR-independent functions in R7 photoreceptor axon targeting. Proc Natl Acad Sci U S A 103:11595-11600.

Johnson KG, Tenney AP, Ghose A, Duckworth AM, Higashi ME, Parfitt K, Marcu O, Heslip TR, Marsh JL, Schwarz TL, Flanagan JG, Van Vactor D (2006) The HSPGs Syndecan and Dallylike bind the receptor phosphatase LAR and exert distinct effects on synaptic development. Neuron 49:517-531.

Kaufmann N, DeProto J, Ranjan R, Wan H, Van Vactor D (2002) Drosophila liprin-alpha and the receptor phosphatase Dlar control synapse morphogenesis. Neuron 34:27-38.

Ko J, Kim S, Valtschanoff JG, Shin H, Lee JR, Sheng M, Premont RT, Weinberg RJ, Kim E (2003a) Interaction between liprin- $\alpha$ and GIT1 is required for AMPA receptor targeting. J Neurosci 23:1667-1677.

Ko J, Na M, Kim S, Lee JR, Kim E (2003b) Interaction of the ERC family of RIM-binding proteins with the liprin-alpha family of multidomain proteins. J Biol Chem 278:42377-42385.

Kriajevska M, Fischer-Larsen M, Moertz E, Vorm O, Tulchinsky E, Grigorian M, Ambartsumian N, Lukanidin E (2002) Liprin beta 1, a member of the family of LAR transmembrane tyrosine phosphatase-interacting proteins, is a new target for the metastasis-associated protein S100A4 (Mts1). J Biol Chem 277:5229-5235.

Liebl FL, Wu Y, Featherstone DE, Noordermeer JN, Fradkin L, Hing H (2008) Derailed regulates development of the Drosophila neuromuscular junction. Dev Neurobiol 68:152-165.

Maurel-Zaffran C, Treisman JE (2000) pannier acts upstream of wingless to direct dorsal eye disc development in Drosophila. Development 127:1007-1016.

Maurel-Zaffran C, Suzuki T, Gahmon G, Treisman JE, Dickson BJ (2001) Cell-autonomous and -nonautonomous functions of LAR in R7 photoreceptor axon targeting. Neuron 32:225-235.

McCabe BD, Marqués G, Haghighi AP, Fetter RD, Crotty ML, Haerry TE, Goodman CS, O'Connor MB (2003) The BMP homolog Gbb provides a retrograde signal that regulates synaptic growth at the Drosophila neuromuscular junction. Neuron 39:241-254.

Meruelo AD, Bowie JU (2009) Identifying polymer-forming SAM domains. Proteins 74:1-5.

Miller KE, DeProto J, Kaufmann N, Patel BN, Duckworth A, Van Vactor D (2005) Direct observation demonstrates that Liprin-alpha is required for trafficking of synaptic vesicles. Curr Biol 15:684-689.

Morante J, Desplan C (2008) The color-vision circuit in the medulla of Drosophila. Curr Biol 18:553-565.

Moses K, Rubin GM (1991) glass encodes a site-specific DNA-binding protein that is regulated in response to positional signals in the developing Drosophila eye. Genes Dev 5:583-593.

Nachat R, Cipolat S, Sevilla LM, Chhatriwala M, Groot KR, Watt FM (2009) KazrinE is a desmosome-associated liprin that colocalises with acetylated microtubules. J Cell Sci 122:4035-4041.

Newsome TP, Schmidt S, Dietzl G, Keleman K, Asling B, Debant A, Dickson BJ (2000) Trio combines with Dock to regulate Pak activity during photoreceptor axon pathfinding in Drosophila. Cell 101:283-294. 
Norrmén C, Vandevelde W, Ny A, Saharinen P, Gentile M, Haraldsen G, Puolakkainen P, Lukanidin E, Dewerchin M, Alitalo K, Petrova TV (2010) Liprin-betal is highly expressed in lymphatic vasculature and is important for lymphatic vessel integrity. Blood 115:906-909.

Olsen O, Moore KA, Fukata M, Kazuta T, Trinidad JC, Kauer FW, Streuli M, Misawa H, Burlingame AL, Nicoll RA, Bredt DS (2005) Neurotransmitter release regulated by a MALS-liprin-alpha presynaptic complex. J Cell Biol 170:1127-1134.

Owald D, Fouquet W, Schmidt M, Wichmann C, Mertel S, Depner H, Christiansen F, Zube C, Quentin C, Körner J, Urlaub H, Mechtler K, Sigrist SJ (2010) A Syd-1 homologue regulates pre- and postsynaptic maturation in Drosophila. J Cell Biol 188:565-579.

Packard M, Koo ES, Gorczyca M, Sharpe J, Cumberledge S, Budnik V (2002) The Drosophila Wnt, wingless, provides an essential signal for pre- and postsynaptic differentiation. Cell 111:319-330.

Patel MR, Lehrman EK, Poon VY, Crump JG, Zhen M, Bargmann CI, Shen K (2006) Hierarchical assembly of presynaptic components in defined $C$. elegans synapses. Nat Neurosci 9:1488-1498.

Pawson C, Eaton BA, Davis GW (2008) Formin-dependent synaptic growth: evidence that Dlar signals via Diaphanous to modulate synaptic actin and dynamic pioneer microtubules. J Neurosci 28:11111-11123.

Rawson JM, Lee M, Kennedy EL, Selleck SB (2003) Drosophila neuromuscular synapse assembly and function require the TGF-beta type I receptor saxophone and the transcription factor Mad. J Neurobiol 55:134-150.

Saitoe M, Tanaka S, Takata K, Kidokoro Y (1997) Neural activity affects distribution of glutamate receptors during neuromuscular junction formation in Drosophila embryos. Dev Biol 184:48-60.

Schoch S, Castillo PE, Jo T, Mukherjee K, Geppert M, Wang Y, Schmitz F, Malenka RC, Südhof TC (2002) RIMlalpha forms a protein scaffold for regulating neurotransmitter release at the active zone. Nature 415:321-326.

Serra-Pagès C, Kedersha NL, Fazikas L, Medley Q, Debant A, Streuli M (1995) The LAR transmembrane protein tyrosine phosphatase and a coiled-coil LAR-interacting protein co-localize at focal adhesions. EMBO J 14:2827-2838.

Serra-Pagès C, Medley QG, Tang M, Hart A, Streuli M (1998) Liprins, a family of LAR transmembrane protein-tyrosine phosphatase-interacting proteins. J Biol Chem 273:15611-15620.
Serra-Pagès C, Streuli M, Medley QG (2005) Liprin phosphorylation regulates binding to LAR: evidence for liprin autophosphorylation. Biochemistry 44:15715-15724.

Shin H, Wyszynski M, Huh KH, Valtschanoff JG, Lee JR, Ko J, Streuli M, Weinberg RJ, Sheng M, Kim E (2003) Association of the kinesin motor KIF1A with the multimodular protein liprin-alpha. J Biol Chem 278:11393-11401.

Spangler SA, Hoogenraad CC (2007) Liprin-alpha proteins: scaffold molecules for synapse maturation. Biochem Soc Trans 35:1278-1282.

Stewart BA, Schuster CM, Goodman CS, Atwood HL (1996) Homeostasis of synaptic transmission in Drosophila with genetically altered nerve terminal morphology. J Neurosci 16:3877-3886.

Takemura SY, Lu Z, Meinertzhagen IA (2008) Synaptic circuits of the Drosophila optic lobe: the input terminals to the medulla. J Comp Neurol 509:493-513.

van Roessel P, Elliott DA, Robinson IM, Prokop A, Brand AH (2004) Independent regulation of synaptic size and activity by the anaphasepromoting complex. Cell 119:707-718.

Wagh DA, Rasse TM, Asan E, Hofbauer A, Schwenkert I, Dürrbeck H, Buchner S, Dabauvalle MC, Schmidt M, Qin G, Wichmann C, Kittel R, Sigrist SJ, Buchner E (2006) Bruchpilot, a protein with homology to ELKS/ CAST, is required for structural integrity and function of synaptic active zones in Drosophila. Neuron 49:833-844.

Wagner OI, Esposito A, Köhler B, Chen CW, Shen CP, Wu GH, Butkevich E, Mandalapu S, Wenzel D, Wouters FS, Klopfenstein DR (2009) Synaptic scaffolding protein SYD-2 clusters and activates kinesin-3 UNC-104 in C. elegans. Proc Natl Acad Sci U S A 106:19605-19610.

Wyszynski M, Kim E, Dunah AW, Passafaro M, Valtschanoff JG, Serra-Pagès C, Streuli M, Weinberg RJ, Sheng M (2002) Interaction between GRIP and liprin-alpha/SYD2 is required for AMPA receptor targeting. Neuron 34:39-52.

Yoshihara M, Adolfsen B, Galle KT, Littleton JT (2005) Retrograde signaling by Syt 4 induces presynaptic release and synapse-specific growth. Science 310:858-863.

Zhen M, Jin Y (1999) The liprin protein SYD-2 regulates the differentiation of presynaptic termini in C. elegans. Nature 401:371-375. 